\title{
Os fatores que influenciam o processo de tomada de decisão dos consumidores de cervejas artesanais
}

Gleidson Rodrigues da Silva

Trabalho de Conclusão de Curso

CENTRO de CIÊNCIAS SOCIAIS - CCS

DEPARTAMENTO DE ADMINISTRAÇÃO

Graduação em Administração de Empresas 
Gleidson Rodrigues da Silva

Os fatores que influenciam o processo de tomada de decisão dos consumidores de cervejas artesanais

Trabalho de Conclusão de Curso

Trabalho de Conclusão de Curso, apresentado ao programa de graduação em Administração da PUC-Rio como requisito parcial para a obtenção do título de graduação em Administração.

Orientador: Joao Renato de Souza Coelho Benazzi

Rio de Janeiro, novembro de 2017. 


\section{Agradecimentos}

À Deus, por ter me dado forças para superar todas as dificuldades.

À PUC-Rio, seu corpo docente, ao departamento de administração e à coordenação, por transformar seus graduandos em excelentes profissionais.

Ao meu orientador, Joao Renato de Souza Coelho Benazzi, pelo apoio na elaboração deste trabalho.

Aos meus pais, e minha família pelo apoio incondicional.

E aos meus amigos e companheiros de trabalho que tiveram papel fundamental no apoio, no exemplo e na motivação ao longo da minha trajetória. 


\section{Resumo}

da Silva, Gleidson Rodrigues. Os fatores que influenciam o processo de tomada de decisão dos consumidores de cervejas artesanais. Rio de Janeiro, 2017. p.44. Trabalho de Conclusão de Curso - Departamento de Administração. Pontifícia Universidade Católica do Rio de Janeiro.

Este trabalho visa compreender quais são os principais elementos considerados pelos consumidores de cervejas artesanais durante o seu processo de tomada de decisão de compra, aumentar o entendimento sobre a percepção deste segmento de mercado, permitindo uma melhora da comunicação das cervejarias artesanais com o seu público alvo. Para isso, utilizou-se uma etapa de pesquisa exploratória com os empresários do mercado, referências bibliográficas e um questionário com consumidores e não consumidores de cervejas artesanais no estado do Rio de Janeiro. Permitindo assim, uma melhora na comunicação por parte dos produtores com o mercado consumidor de cervejas artesanais, favorecendo a aplicação dos recursos nos fatores com o maior impacto sobre o consumo.

\section{Palavras-chave}

Cerveja artesanal, consumidor, mercado, decisão de compra. 


\section{Abstract}

Da Silva, Gleidson Rodrigues. The factors influencing the decision-making process of the consumers of handmade beers. Rio de Janeiro, 2017. P. 44. Trabalho de Conclusão de Curso - Departamento de Administração. Pontifícia Universidade Católica do Rio de Janeiro.

This work aims to understand what are the main elements considered by the consumers of artisanal beers during the purchase decision making process, increasing the understanding about the perception of this market segment, enabling the improvement of the communication of artisanal breweries with their public- target. For this, an exploratory research step was used with market entrepreneurs, bibliographical references and a questionnaire with consumers and non-consumers of artisanal beers in the state of Rio de Janeiro. Thus, enabling an improvement in the communication of the producers with the consumer market of artisan beers, encouraging the application of resources in factors with the greatest impact on consumption.

Key-words

Craft beer, consumer, market, purchasing decision. 


\section{Sumário}

1 O tema e o problema de estudo 1

1.1. Introdução ao tema e ao problema do estudo 1

1.2. Objetivo do estudo 3

1.3. Objetivos intermediários do estudo 4

1.4. Delimitação e foco do estudo 5

1.5. Justificativa e relevância do estudo 5

2 Referencial teórico $\quad 7$

$\begin{array}{ll}\text { 2.1. Posicionamento } & 7\end{array}$

2.2. Tomada de decisão 8

$\begin{array}{ll}\text { 2.3. Branding } & 10\end{array}$

3 Método e procedimento de coleta e análise de dados do estudo 13

3.1. Etapas de coleta de dados 13

3.2. Fontes de informação selecionadas para coleta de dados no estudo14

3.3. Procedimentos e instrumentos de coleta de dados utilizados no $\begin{array}{ll}\text { estudo } & 16\end{array}$

3.4. Formas de tratamento e análise dos dados coletados para o estudo 17

$\begin{array}{ll}\text { 3.5. Limitações do Estudo } & 18\end{array}$

4 Apresentação e análise dos resultados 20

4.1. Descrição do perfil dos entrevistados 20

4.2. Descrição e análise dos resultados do método qualitativo 21

4.3. Descrição do perfil dos respondentes do questionário 25

4.4. Descrição e análise dos resultados do método quantitativo 26

5 Conclusões e recomendações para novos estudos 40

5.1. Sugestões e recomendações para novos estudos 42

6 Referências Bibliográficas 43 


\section{Lista de Tabelas}

Tabela 1 - Tabela grau de envolvimento x gasto mensal médio - Fonte: Autor.. 30 Tabela 2 - Tabela grau de envolvimento x gasto mensal médio (\%) - Fonte: Autor 30

\section{Lista de Figuras}

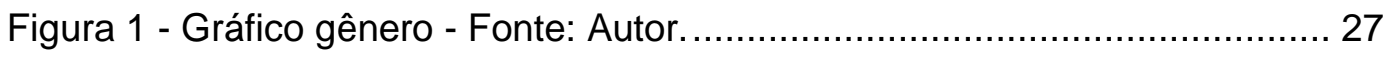

Figura 2 - Gráfico faixa etária - Fonte: Autor................................................ 27

Figura 3 - Gráfico formação acadêmica - Fonte: Autor..................................... 28

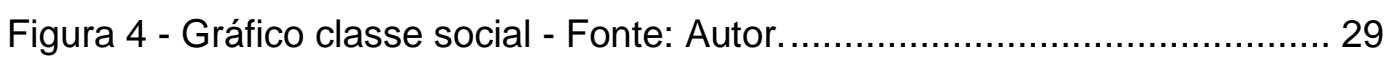

Figura 5 - Gráfico comparação de fatores - Fonte: Autor.................................. 31

Figura 6 - Comparação de fatores x grau de envolvimento $(<5)$ - Fonte: Autor. 32

Figura 7 - Comparação de fatores $x$ grau de envolvimento (=5) - Fonte: Autor.. 32

Figura 8 - Comparação de fatores $x$ grau de envolvimento (>5) - Fonte: Autor.. 33

Figura 9 - Gráfico fator preço - Fonte: Autor............................................... 34

Figura 10 - Gráfico fator sabor/estilo - Fonte: Autor....................................... 35

Figura 11 - Gráfico fator indicação - Fonte: Autor ............................................ 35

Figura 12 - Gráfico fator marca - Fonte: Autor.............................................. 36

Figura 13 - Gráfico cenário opção de compra para presente - Fonte: Autor. …. 37

Figura 14 - Gráfico cenário opção de compra para consumo em casa - Fonte: Autor. 37

Figura 15 - Gráfico cenário de compra para consumo em bares/restaurantes Fonte: Autor. 


\section{0 tema e o problema de estudo}

\subsection{Introdução ao tema e ao problema do estudo}

O Brasil é um dos líderes mundiais de produção e consumo de cerveja, ficando atrás apenas da China e dos Estados Unidos (SEBRAE, 2015). Trata-se de um mercado gigantesco cujos números foram levantados em 2014 por uma pesquisa realizada pela Fundação Getúlio Vargas para a Associação Brasileira da Indústria da Cerveja (Cerv Brasil) e demonstram que o mercado movimentou $\mathrm{R} \$ 74$ bilhões, respondendo por 1,6\% do PIB nacional, gerando $\mathrm{R} \$ 21$ bilhões em tributos, com uma participação na indústria de transformação de $14 \%$ gerando, 2,2 milhões de empregos diretos, indiretos e induzidos.

O setor cervejeiro é um dos mais tradicionais do Brasil, criado em 1853, tem ampla capilaridade e está presente em todas as cidades do país, em uma cadeia que vai do agronegócio ao pequeno varejo, passando pelos mercados de embalagens, maquinário, logística e construção civil.

Nesse contexto, observamos o surgimento do segmento de mercado das cervejas artesanais. Esse mercado vem crescendo ao longo dos últimos anos tanto no Brasil como em outros lugares do mundo, apresentando mercados consolidados e outros em processo de consolidação, segundo dados divulgados pelo Instituto da Cerveja Brasil (2016).

Considerando a consolidação do mercado no Brasil observamos que o segmento ainda apresenta fôlego para crescer, principalmente ao compararmos com os EUA onde o mercado de cervejas artesanais corresponde a $12 \%$. Podemos considerar que existe ainda no Brasil um lastro para o crescimento desse segmento, já que o mercado de cervejas artesanais no país corresponde apenas a $0,7 \%$ do mercado total, segundo dados divulgados pelo Instituto da Cerveja Brasil (2016).

Ainda segundo o estudo divulgado pela Instituto da Cerveja Brasil (2016), no Brasil até o ano de 2015 existiam 372 cervejarias, mostra um crescimento de 17\% se comparado com o ano anterior, já em 2016 o MAPA registrou um crescimento em número de cervejarias de 148 unidades, o que corresponde a um aumento de $40 \%$, essas cervejarias estão concentradas nas regiões Sul e Sudeste com $91 \%$ do total destas empresas estabelecidos nestas regiões, o 
estado do Rio de Janeiro aparece em sexto lugar em número total de cervejarias.

A variedade de produtos tem alterado o padrão de consumo e as escolhas dos consumidores. Os brasileiros estão optando por beber menos, porém melhor. E para isso, escolhem as cervejas artesanais e Premium, consideradas cervejas especiais, que têm melhor custo-benefício, segundo estudo apresentado pelo setor de inteligência setorial do SEBRAE (2015).

Este estudo revelou ainda que o perfil do consumidor de cervejas artesanais: como sendo majoritariamente composto por homens, jovens entre 25 e 31 anos, com um elevado nível de interações em mídias sociais e em sua maioria com nível superior. Esse público consome de uma a três garrafas por ocasião de consumo, que em sua maioria são compradas em supermercados, bares, adegas e empórios especializados, com um investimento por produto variando entre $R \$ 11,00$ e $R \$ 50,00$. Esse público tem por hábito consumir a cerveja com amigos ou sozinhos, principalmente em casa e em finais de semana.

O mercado de cervejas artesanais tem crescido cerca de $20 \%$ ao ano na última década, e esse crescimento pode ser atribuído ao aumento do número de consumidores, ao apetite de investidores por negócios rentáveis e de forte crescimento e aos produtores artesanais que se profissionalizam, muitas vezes motivados pela crise que o Brasil enfrenta desde 2014 e que buscam novas alternativas de negócios, Bressiani (2017).

Sendo assim, ao considerarmos o tamanho potencial do mercado, o seu crescimento e o perfil dos seus consumidores se faz necessário entender: Quais são os fatores que influenciam o consumidor? O que os motiva a comprar? Como atingir esse consumidor? Onde aplicar os seus esforços de marketing? 0 que o consumidor considera no seu momento de compra? O que pode impactar nesse processo? Todas essas informações são importantes para uma estratégia adequada de marketing por parte das cervejarias, que competem em um mercado crescente e com imensa variedade de produtos. O cenário atual das cervejarias é de incerteza quanto aos atributos que o novo consumidor considera relevante, os modelos de cervejarias de massa não se aplicam nesse novo contexto, por isso, entender as motivações dos consumidores é cada vez mais importante.

Baseado no cenário descrito acima, o presente estudo visa responder a seguinte questão: quais os fatores que influenciam o processo de tomada de decisão dos consumidores de cervejas artesanais? 


\subsection{Objetivo do estudo}

Este trabalho tem como objetivo final avaliar, quais os fatores que influenciam o processo de tomada de decisão dos consumidores de cervejas artesanais.

A determinação de fatores únicos e universais é de difícil mensuração, porém o presente estudo pretende determinar a influência de seis fatores préselecionados: a marca, o sabor, o rótulo, o preço, a disponibilidade do produto ao cliente e a indicação referenciada, relacionados com o grau de envolvimento destes consumidores com o mercado de cervejas artesanais. Esses fatores foram escolhidos considerando os principais aspectos do produto como a marca, o sabor, o preço e o rótulo que são elementos atribuídos ao produto e que geram identificação, de aspectos dos pontos de venda como indicação e disponibilidade que impactam diretamente no momento de compra do consumidor e o grau de envolvimento do consumidor, esse dado permite maior entendimento sobre os diferentes perfis de consumidor e as suas relações com o produto e o ponto de venda. Considerando ainda, a relação das cervejarias artesanais e sua variedade de marcas, sabores, rótulos, envolvimento dos clientes, pontos de vendas especializados com as cervejas de massa, amplamente distribuídas e com menor diversidade de marcas e estilos.

A determinação do impacto de cada uma dessas variáveis, pode permitir uma melhora no desenvolvimento de produtos e de ações que visam o atingimento de um determinado público alvo. Através do entendimento da percepção destes fatores por parte dos consumidores, as cervejarias e os pontos de venda de cervejas artesanais poderão adequar as suas estratégias de marketing com um maior nível de informações sobre o seu consumidor, melhorando o desempenho das vendas e da marca. 


\subsection{Objetivos intermediários do estudo}

Para alcançar o objetivo final proposto para esse estudo foi estipulado, como objetivos intermediários a serem alcançados:

$\checkmark$ Investigar o grau de envolvimento do consumidor com o mercado de cervejas artesanais

Este primeiro ponto é determinante para o entendimento da percepção dos consumidores e de como eles se relacionam com o mercado de cervejas artesanais, entendendo o quanto o nível de envolvimento com este universo, ou seja, o grau de conhecimento que o consumidor apresenta sobre a variabilidade dos etilos e escolas cervejeiras, impacta na sua percepção de qualidade e influência seus estímulos de compra, além de permitir uma segmentação de público alvo por nível de envolvimento.

$\checkmark$ Identificar o impacto de cada fator selecionado no processo de compra e o sobre o consumo

A identificação dos fatores pré-selecionados e que que envolvem os critérios de tomada de decisão do consumidor durante o processo de compra é fundamental, para que se entenda quais as ações de marketing promovidas pelas cervejarias geram maior impacto na tentativa de atingir os seus consumidores potenciais.

$\checkmark$ Entender a percepção do público alvo sobre os aspectos que compõem o produto

Entendendo os aspectos do produto pela ótica dos consumidores, torna possível compreender se os esforços empregados pelas cervejarias em atrair o seu público alvo estão sendo compreendidas de forma a trazer resultados concretos sobre suas vendas e consolidação de marca.

$\checkmark$ Propor ações de marketing baseadas nas análises dos dados coletados, a fim de mensurar o ganho que o entendimento da percepção do consumidor pode proporcionar para uma marca. 
Conhecendo o perfil dos consumidores de cervejas artesanais, seus critérios de decisão de compra, seu ponto de vista do produto e o seu grau de envolvimento com o universo das cervejas artesanais, é possível analisar as informações coletas e propor ações de marketing baseadas na mensuração de impacto de cada variável observada, a fim de encontrar novas soluções que potencializem o ganho que o entendimento da percepção do consumidor pode proporcionar para uma marca, correlacionando com o posicionamento de público que a marca deseja atingir.

\subsection{Delimitação e foco do estudo}

O estudo elaborado tem como foco o mercado carioca de consumidores de cervejas artesanais que possuem diferentes níveis de envolvimento com esse universo e os não consumidores de cervejas artesanais, ou seja, os que apenas consomem cervejas de massa, mas que são potenciais consumidores.

Outro ponto importante da delimitação é que, dentre diversas variáveis envolvidas no ato de consumir cerveja, foram determinadas seis variáveis de influência sobre o consumidor que foram descritas no objetivo final e estas variáveis foram confrontadas com o nível de envolvimento do consumidor com o mercado de cervejas artesanais.

\subsection{Justificativa e relevância do estudo}

O universo do consumo de cervejas artesanais é amplo e diversificado, o consumidor opta pela experimentação, o número de opções é cada vez maior no cenário carioca e brasileiro, entender o consumidor e os fatores que são determinantes em sua motivação de compra é um importante aspecto para a diferenciação e visibilidade das diversas marcas.

O presente estudo tem por objetivo aumentar a compreensão de como o consumidor de cerveja artesanal percebe as diferentes variáveis que compõem o produto e confrontar com os esforços dos produtores em atingir o seu público alvo buscando assim, compreender o real impacto desses esforços na motivação do consumo.

Sendo assim, o trabalho abordou as principais características das cervejas artesanais tais como: a influência do sabor na motivação de consumo, o impacto 
do rótulo na tomada de decisão do consumidor, a influência da marca sobre a escolha do consumidor, o poder que as fontes de informação têm sobre o consumo nesse mercado, o peso da disponibilidade das cervejas no momento da compra, o quanto o fator preço é determinante para os consumidores, relacionando todos esses elementos com o nível de envolvimento dos consumidores com o mercado de cervejas artesanais.

O estudo permitirá que as cervejarias e os pontos de venda tenham uma melhor percepção dos principais elementos que os consumidores consideram na hora de escolher a cerveja, permitindo assim uma melhora nos esforços de venda e promoção desse universo, aumentando as chances de sucesso de uma marca frente as demais.

Os resultados alcançados nesse estudo também poderão ser utilizados em futuras pesquisas e trabalhos acadêmicos, tendo em vista que dispõe de reflexões sobre o comportamento de consumidores de um segmento de mercado que vem crescendo cada vez mais em interesse e relevância econômica. 


\section{Referencial teórico}

Neste capítulo são apresentados e discutidos aspectos conceituais e estudos relacionados ao tema de estudo em investigação, que servirão de base para a análise realizada.

A primeira seção aborda a questão referentes ao posicionamento do produto. $\mathrm{Na}$ segunda, são abordados conceitos do comportamento do consumidor, abordando a percepção, as motivações e valores e a tomada de decisão do consumidor. Por último o conceito de marca é abordado. O entendimento destes tópicos se faz necessário para uma correta avaliação de como é construído o consumo.

\subsection{Posicionamento}

Posicionamento é abordado por Kotler e Keller (2000), como sendo o ato de projetar o produto e a imagem da empresa na mente do público-alvo ocupando um lugar de destaque. Os autores ainda definem que, uma estratégia e marketing eficaz tem sua origem em uma adequada segmentação e seleção de público-alvo sendo a base de sucesso para a estratégia traçada, uma vez que, erros nessa definição tendem a criar problemas quanto ao entendimento do produto e a proposta de valor por parte dos consumidores, impactando de maneira negativa os resultados financeiros e a valorização da marca.

Para Kotler e Keller (2000), uma característica de destaque para uma estratégia de posicionamento bem executada é a necessidade de identificar e trabalhar os pontos de semelhança e de diferença existentes, estabelecendo assim, uma base de referência competitiva fundamentando a estratégia adotada.

Os pontos de semelhança são associações compartilhadas por outros produtos, geralmente dentro de um mesmo segmento de mercado, e são importantes pois apresentam requisitos mínimos esperados pelos consumidores no momento da compra, ainda que estes pontos não promovam a diferenciação, a existência destes pontos mostra a coerência de uma estratégia de posicionamento de produto. Ao considerarmos os pontos de diferenciação, os autores defendem que estes pontos devem ser identificados e trabalhados, 
permitindo aos consumidores criarem uma associação da marca com as qualidades e benefícios apresentados, sendo compreendidos como diferenças positivas com benefícios quase incomparáveis, ou ao menos de difícil alcance pelas marcas concorrentes.

Essa associação sedimenta características únicas na mente do consumidor. E uma outra abordagem defendida por Ries e Trout (1989), define que uma estratégia de posicionamento não necessariamente deve estar centralizada no produto, mas sim considerar o posicionamento na mente do consumidor potencial. Sendo assim, mudanças realizadas na embalagem, nome ou preço do produto, são mudanças que visam exercer uma posição de valor na mente do público-alvo, o que não altera o produto em si.

Os autores defendem ainda que o mercado de consumo passa por uma saturação de propagandas e informações. O que reduz a capacidade do consumidor médio em reter informações dos produtos e das marcas, o que gera uma simplificação dessas informações na mente dos consumidores, através de um processo de filtração e descarte dessas informações, retendo apenas o que foi apresentado de forma clara, bem caracterizada ou interessante para o consumidor.

A eficácia para Ries e Trout (1989), está relacionada a uma forma de mensagem mais simplificada, focada nas características do produto que podem gerar maior impacto sobre o consumidor abrindo mão do destaque de características que apenas o compõe.

Para o mercado de cervejarias artesanais, onde a concorrência está cada vez mais acirrada, saber se posicionar de maneira adequada e impactar o consumidor, se faz cada vez mais necessário para a sobrevivência de novas marcas, por isso entender como o consumidor percebe a marca é essencial para a criação de valor junto ao cliente.

\subsection{Tomada de decisão}

Os consumidores são constantemente confrontados com a necessidade de tomar decisões quanto a produtos e serviços, o ato de tomar decisões é ainda mais complexo devido à variedade de decisões que nos deparamos em um mercado que presa pela hiperescolha.

A tomada de decisão é um processo para Solomon (2011), composto de cinco etapas sequenciais, onde no primeiro momento o consumidor reconhece 0 
problema ou necessidade, busca informações a respeito dos produtos disponíveis, considera as alternativas, escolhe o produto e avalia os resultados. Esse processo pode se dar de modo racional e cognitivo, de maneira instintiva ou reforçada por campanhas promocionais. A maneira em que o consumidor agrupa mentalmente os produtos exerce influência sobre as alternativas que ele irá considerar em compras futuras.

A tomada de decisão pode ser classificada segundo o autor, quanto a quantidade de esforço que a decisão demanda, ela pode ser considerada em um continuum. Onde em um extremo temos a tomada de decisão habitual em que as escolhas são feitas com pouco ou nenhum esforço, no outro extremo temos a tomada de decisão de solução ampliada na qual o consumidor entende que a decisão é importante e carrega um grau de risco considerável e entre os extremos temos a solução limitada do problema que em geral são mais simples, uma vez que, os consumidores não estão dispostos a buscar tantas informações e alternativas nem enxergam um alto risco envolvido.

Outro ponto importante do processo de tomada de decisão destacado por Solomon (2011), diz respeito ao quanto um consumidor pesquisa por um produto, de maneira geral indivíduos com baixo ou alto nível de conhecimento sobre o produto tendem a pesquisar menos quando comparados aos indivíduos que apresentam um moderado nível de conhecimento sobre o produto.

A tomada de decisão sofre impacto ainda, segundo o autor, do que ele define como fatores de risco, que são classificados em cinco grupos distintos incluindo fatores objetivos e subjetivos, segundo Solomon (2011) os riscos podem ser classificados em: monetários, funcionais, físicos, sociais e psicológicos.

A heurística ou regras mentais que levam a uma decisão rápida, também é considerada uma importante ferramenta na tomada de decisão (SOLOMON, 2011). Dentro deste conceito podemos destacar a tendência do indivíduo em escolher uma marca preferida em relação as demais, esse conceito pode ser associado a Lei de Zipf.

"[...]George Kingsley Zipf descobriu que the - a palavra mais usada na língua inglesa - ocorre com quase o dobro da frequência de of (em segundo lugar), quase três vezes mais do que end (terceiro lugar) e assim por diante. "

(SOLOMON, 2011, p.358) 
O método de Fishbein é um interessante modelo para o embasamento deste trabalho, onde o modelo é capaz de medir a atitude do consumidor considerando a relação do peso que o consumidor determina para um atributo com o quanto ele percebe deste atributo na marca/produto.

Outros dois conceitos merecem ser destacados são em primeiro lugar a inércia, definido pelo autor como o ato de comprar uma marca por hábito pela mera exigência de um menor esforços, ao passo que, se por alguma razão surgir um outro produto com maior facilidade de compra, sendo ela da ordem de preço ou disponibilidade o consumidor trocará de marca sem hesitar. Em segundo o conceito de fidelidade à marca, que para Solomon (2011), é o comportamento de compra repetida que reflete uma decisão consciente de continuar consumindo uma determinada marca, essa definição determina que além do consumidor comprar regularmente a marca escolhida a sua atitude de compra é favorável a marca, gerando um apego emocional.

Com o mercado cada vez mais pulverizado e repleto de novas marcas e sabores, compreender quais são os fatores que mais impactam a tomada de decisão do consumidor de cervejas artesanais, se mostra relevante às empresas para aumentar a sua capitação e retenção de clientes, permitindo assim, o emprego de suas forças de marketing nas ações com maior impacto sobre o consumidor.

\subsection{Branding}

O branding tem por objetivo gerar consciência de uma marca na mente do consumidor. De modo que, se não existir quem a reconheça não há marca, a percepção da marca está intimamente ligada à sua existência na mente do consumidor. Para Aaker (1996), a conscientização é medida de acordo com a maneira em que os consumidores lembram de uma determinada marca, passando por níveis de reconhecimento, recordação e culminando ao top of mind e a marca dominante.

"O conhecimento da marca consiste em todos os pensamentos, sensações, imagens, experiências, crenças etc. ligados à marca. Especificamente, elas devem criar associações fortes, favoráveis e exclusivas com os clientes"

(KOTLER; KELLER, 2006, p.271). 
"Pesquisas na área de psicologia demonstram que, de forma isolada, o reconhecimento pode resultar em sensações mais positivas em relação a praticamente qualquer coisa, seja essa coisa música, pessoas, palavras ou marcas. Esses estudos também demonstraram que, mesmo com palavras sem sentido (como "postrina" versus "potastin", por exemplo), os consumidores preferem um item já percebido anteriormente a uma completa novidade.

Assim, quando se escolhe uma marca, a marca familiar terá uma vantagem."

(AAKER, 1996, p. 20)

Sendo assim, o reconhecimento é diretamente proporcional à recordação de uma marca de sucesso. Ou seja, caso uma marca tenha um elevado nível de reconhecimento e baixo nível de recordação o sucesso da marca não está garantido, uma vez que, existe o conhecimento da marca por parte dos consumidores, porém a falta de recordação faz com que a marca não seja lembrada no memento da compra.

O autor define ainda que, o último nível de conscientização é o predomínio da marca registrada, quando o consumidor só consegue indicar o nome de uma única marca - por exemplo, Bombril, Xerox e Maisena. O sucesso absoluto da marca pode ser trágico como adverte Aaker (1996), nos casos em que a marca registrada se converte em denominação comum de produtos não legalmente protegidos - por exemplo a Aspirina, o e o Windsurf que denominaram uma categoria de produtos e acabaram perdendo o seu reconhecimento enquanto marca.

Um aspecto relevante a se considerar é o conceito de brand equity, que é definido por Aaker (1998) como um conjunto de ativos e passivos associados a uma marca, contemplando seu nome e seu símbolo, que podem aumentar ou reduzir o valor proporcionado por um produto ou serviço tanto para a empresa quanto para os consumidores. Podemos entender de forma resumida que 0 objetivo do branding é gerar o branding equity, que é o valor que impacta na forma que o consumidor pensa, sente e age em relação à marca, influenciando diretamente no preço, no market share e na lucratividade da marca, o branding equity representa por tanto um importante ativo intangível, que impacta no valor psicológico e financeira da organização. 
Segundo Crescitelli e Shimp (2012), que apresentam uma perspectiva diferente sobre o branding equity observada sob a ótica do consumidor, destacam que os consumidores tendem a enxergar em uma determinada marca, valores que as pessoas estão familiarizadas e que guardam em suas memórias associações únicas com a marca.

Através dessa associação, são armazenados na memória de consumidor pensamentos e sentimentos acerca da marca. Crescitelli e Shimp (2012) apresentam ainda outro modo de pensar a respeito do brand equity que se fundamenta em duas formas de conhecimento sendo elas: a percepção da marca e a imagem da marca. Onde a percepção está ligada a existência da marca na mente do público, sendo evocada e reforçada por ações promocionais, influenciando o nível de recordação que ela apresenta e a sua retenção na memória aumentando o valor das marcas que apresentam maior destaque de recordação para o indivíduo. Já a imagem da marca, é considerada como as associações que são ativadas na memória quando o consumidor pensa sobre uma marca determinada marca. Elas podem ser avaliadas de acordo com seu nível de favorabilidade, força e singularidade. Assim como, os tipos de associações considerando os atributos, os benefícios e a atitude.

Podemos notar assim, que as cervejarias que desejam ter sucesso em um mercado onde marcas novas surgem em um ritmo acelerado, se faz necessário uma adequada estratégia para se atribuir valor a marca, com enfoque de longo prazo, promovendo o contato constante com os indivíduos e a diferenciação da marca na mente do consumidor. 


\section{Método e procedimento de coleta e análise de dados do estudo}

\subsection{Etapas de coleta de dados}

A pesquisa foi realizada em três etapas distintas, a fim de, obter o maior número de informações acerca do assunto abordado no presente estudo.

A primeira etapa que compôs o estudo foi a fase de pesquisa de dados secundários, na segunda foi realizada uma pesquisa exploratória de caráter qualitativo com o objetivo de confirmar ou alterar as variáveis levantadas na etapa anterior e a terceira etapa de caráter quantitativo, teve por objetivo aumentar a precisão do estudo através de uma amostra representativa do universo estudado.

Com a primeira etapa, se buscou levantar os dados do mercado e as informações disponíveis sobre o setor, com essas informações se levantou as variáveis que o presente estudo pretende investigar, a fim de, entender a tomada de decisão do consumidor durante a compra de cervejas artesanais, essas variáveis foram descritas no tópico, objetivo de estudo.

$\mathrm{Na}$ segunda etapa, realizada através de entrevistas com especialistas do setor que representam diferentes atores do mercado, buscou-se confirmar a importância das variáveis selecionadas e a relevância do estudo, além de buscar outras informações que poderiam ser pertinentes e complementares ao estudo proposto.

Por fim, com o intuído de mensurar uma amostra mais precisa dentro do universo do estudo foi realizada uma pesquisa quantitativa através de um questionário que foi distribuído de forma virtual para o maior número de respondentes possíveis, considerando a limitação deste estudo.

Tanto as entrevistas que compõem a segunda etapa quanto o questionário da fase quantitativa do estudo, podem ser classificados como pesquisas descritivas, que têm por objetivo trazer luz sobre os hábitos de consumo de cervejas artesanais no Rio de Janeiro. Tanto a pesquisa quantitativa quanto a pesquisa qualitativa devem ser aplicadas de maneira complementar, permitindo 
que se obtenha um maior número de informações sobre o tema, aumentando assim, a compreensão por parte do pesquisador.

\subsection{Fontes de informação selecionadas para coleta de dados no estudo}

$\mathrm{Na}$ primeira etapa, os dados secundários foram coletados através de estudos publicados por entidades da área industrial, como SEBRAE, associações de produtores, como o Instituto da Cerveja Brasil, a CervBrasil, ABRACERVA, Acerva Carioca e entrevistas com especialistas do setor publicadas em jornais e revistas de grande circulação como O Globo, Exame, IstoÉ, Estadão. Esta etapa teve por objetivo levantar as variáveis de interesse para o estudo. Nesta etapa foram analisados os dados mais recentes dentro da disponibilidade dessas informações.

$\mathrm{Na}$ segunda etapa, foi realizada através de pesquisa, pelo método de entrevista, com quatro especialista do mercado. Os entrevistados foram selecionados dentro de uma lógica de grau de envolvimento com o universo de cerveja artesanal e acessibilidade, buscando assim, contar com a visão e a percepção de diferentes atores deste contexto, foram selecionados os seguintes perfis: empresário cervejeiro (cigano) ${ }^{1}$, ou seja, o dono da marca, que desenvolve o produto e vende ao ponto de venda, mas não possui fábrica; empresário cervejeiro (fábrica), ou seja, assim como o perfil anterior ele possui marca própria mas vende a sua capacidade ociosa para as cervejarias ciganas; o perfil empresário do varejo de cervejas artesanais, que compra o produto das cervejarias e vende ao consumidor final e o perfil sommelier, profissional que detém o conhecimento desde a produção da bebida até o relacionamento com clientes. Esses perfis foram selecionados pela sua imersão no mercado de cervejas artesanais e a sua experiência com o setor.

Na terceira e última etapa que é composta pelo questionário online, a sua escolha se deu pela acessibilidade que o modelo proporciona, a capacidade de atingir um maior número de pessoas e o fato de estas se sentirem mais à vontade para responderem as perguntas de forma anônima.

\footnotetext{
1 O método cigano de produção é utilizado por pequenos produtores que pretendem introduzir seus rótulos artesanais no mercado, mas ainda não têm a própria fábrica, alugando o espaço ocioso de outras cervejarias.
} 
Nesta etapa buscou-se em um primeiro estágio medir o grau de envolvimento da amostra com o consumo de cervejas artesanais.

No segundo estágio foi desenvolvida uma questão para a aplicação do método de análise conjunta, nesta questão foram desenvolvidos cartões com combinações das variáveis: preço, sabor/estilo, indicação e marca, considerando os níveis de cada fator, produzindo uma combinação $(3 \times 3 \times 3 \times 2)$ formando 54 combinações diferentes, entre os fatores e seus níveis, foram selecionados apenas 12 cartões com o objetivo de aumentar a aplicabilidade da pesquisa, pois um número excessivo de estímulos é um fator limitante, pela capacidade de diferenciação das opções pelo respondente.

O respondente deveria numerar como 1 , o cartão de maior preferência e como 12, o de menor preferência, estes cartões foram desenvolvidos segundo a seguinte logica: no fator preço, foram atribuídos 3 níveis $(R \$ 19,90, R \$ 24,90$ e $R \$ 29,90)$, foi considerado o menor valor como o atributo mais importante desse fator e o maior, o menos importante.

No fator sabor/estilo, foram atribuídos 3 níveis (Pilsen², Trigo ${ }^{3}, \mathrm{IPA}^{4}$ ), esses níveis foram escolhidos segundo a lógica de familiaridade para os respondentes e pelo fato de serem encarados como estilos iniciantes aos consumidores, para este fator foi considerado o estilo Pilsen como o atributo menos importante e 0 estilo IPA como o atributo de maior importância para o consumidor.

No fator indicação, foram atribuídos 3 níveis (Vendedor, Amigo e Blog), esses 3 níveis foram selecionados considerando a influência do vendedor no momento da venda como o atributo menos importante e a busca de informações anteriores a compra em Blogs especializados com 0 atributo de maior importância.

2 Pilsen, é um tipo de cerveja lager, leve e refrescante, caracterizada por um lúpulo acentuado no aroma e sabor,

3 Trigo, são cervejas claras e opacas, onde sobressai o sabor do trigo com o qual foram produzidas, bem como sabores frutados (banana e maça), cravo e florais.

${ }^{4}$ Indian Pale Ale ou somente IPA, cerveja carregada em lúpulo, criada pelos ingleses para aumentar o tempo de conservação da cerveja que seria levada para as viagens pela Índia. Varia na intensidade de amargor e percentual de álcool de acordo com o subtipo. 
No fator marca, foram atribuídos 2 níveis (Eisenbahn, Hocus Pocus), essas marcar foram selecionadas segundo a lógica de identificação com o movimento artesanal, onde a Eisenbahn por ser uma marca artesanal adquirida pela Brasil Kirin, uma cervejaria de grande porte, seria o atributo de menor importância para o consumidor, frente a marca Hocus Pocus, que mantém a identificação artesanal.

No terceiro estágio do questionário foram desenvolvidas questões que buscavam entender o consumo em diferentes cenários e a importância de cada variável em cada cenário, nesta questão foi solicitado ao respondente que ordenasse as variáveis mais importantes considerando o cenário proposto, onde na primeira posição estaria a opção mais importante e na última posição o menos importante.

No último estágio do questionário foram levantadas questões para a identificação do perfil demográfico da amostra.

Tanto o roteiro das entrevistas quanto o questionário podem ser observados na seção anexo do presente trabalho.

\subsection{Procedimentos e instrumentos de coleta de dados utilizados no estudo}

$\mathrm{Na}$ primeira etapa, os dados secundários foram analisados e serviram como base para realização do levantamento das variáveis de interesse para o estudo. Os dados foram obtidos através de pesquisas em fontes de informação como: jornais, artigos acadêmicos, empresas do setor e blogs especializados. Esse modelo de coletas de dados foi escolhido pelo seu fácil acesso, baixo custo e o amplo número de informações.

Após a primeira etapa, foi desenvolvido um roteiro de entrevista para ser aplicado aos perfis de especialistas, com o objetivo de confirmar a relevância das variáveis selecionadas. Essa segunda etapa consistiu em realizar entrevistas, essas entrevistas foram realizadas entre os dias 23 e 30 de outubro, e tiveram por objetivo de ampliar e aprofundar as informações que serviram como base para o desenvolvimento do questionário. As questões seguiram a lógica de apresentação do entrevistado, envolvimento do entrevistado com o universo das cervejas artesanais, percepção dos entrevistados sobre o público alvo e suas motivações de consumo e percepção do entrevistado sobre o mercado atual. Essas entrevistas foram realizadas através de contato pessoal e 
software de mensagens instantâneas. O roteiro da entrevista está disponível no anexo I do presente trabalho.

Por fim, foi aplicado um questionário online através da plataforma Qualtrics, esta plataforma foi utilizada para a elaboração do questionário, distribuição e coleta dos dados, com o objetivo de conseguir uma amostra mais representativa do público alvo estudado. As questões contidas nesta etapa são fruto dos dados levantados nas duas etapas anteriores, o questionário foi aplicado por meio de distribuição online, esse método foi escolhido pelo seu maior poder de propagação da pesquisa e a facilidade de acesso para os respondentes.

\subsection{Formas de tratamento e análise dos dados coletados para o estudo}

Na primeira etapa que compôs o estudo, a fase de pesquisa de dados secundários, esses dados foram selecionados e analisados e serviram como base para o levantamento das variáveis que foram estudadas neste trabalho.

Durante a segunda etapa, a etapa qualitativa do estudando, considerando se tratar de uma pesquisa não-probabilística, se utilizando de um modelo de pesquisa descritiva, através de entrevista realizada com especialistas do setor de cervejas artesanais, que tinha por objetivo a confirmação das variáveis testadas durante a fase quantitativa do estudo. Nesta etapa foram entrevistados os seguintes perfis de especialistas do setor: o perfil A sócio de cervejaria com produção cigana, ou seja, não possui fábrica própria, o perfil $B$, proprietário de fábrica de cervejas que produz o próprio rótulo e produz para cervejarias ciganas, o perfil $\mathrm{C}$, sócio de uma loja especializada em cervejas artesanais, localizada na região da Tijuca e o perfil $\mathrm{D}$, sommelier de cervejas.

Para a etapa quantitativa, o modelo de análise estatístico que foi empregado neste trabalho foi o método de análise conjunta, esse método é amplamente utilizado pelas empresas que pretendem aumentar a profundidade do entendimento dos hábitos de consumos e o processo de tomada de decisões de seus clientes, pois fornece uma forma de os clientes atribuírem valores numéricos as suas predileções sobre os atributos dos produtos propostos.

Segundo Malhotra (2001), a análise conjunta pretende determinar a importância relativa que os consumidores associam aos atributos relevantes e a utilidade associada aos níveis de atributos. 
A técnica tem a sua importância por suprir a necessidade de transformar a importância relativa percebida pelo respondente, ao comparar um atributo com outro, em uma medida mensurável quantitativamente. Ela consiste em apresentar aos consumidores diferentes combinações entre fatores e níveis de atributos, os níveis são os possíveis valores de cada fator, o fator é a variável que o pesquisador define e que representa um atributo especifico que o pesquisador deseja estudar.

O respondente avalia estímulos propostos no estudo, através da sua percepção e escolha sobre os atributos selecionados, o estímulo vem a ser o conjunto de fatores e níveis propostos pelo pesquisador, Malhotra (2001). O uso de estímulos proporciona ao pesquisador a oportunidade de entender a estrutura de preferência do consumidor considerando o objeto de estudo. A estruturação da preferência tem o papel de explicar o impacto de cada fator na tomada de decisão do entrevistado, além do impacto dos diferentes níveis dentro de um fator no processo de tomada de decisão. Os dados foram extraídos da plataforma Qualtrics e tabulados e calculados pelo autor, com o auxílio do software Microsoft Excel 2013, onde foram calculadas as médias de cada arranjo (cartão) e as médias de cada nível, os dados foram transformados em escala, permitindo assim, um melhor entendimento da relevância de cada fator e seus níveis para o consumidor de cervejas artesanais.

As outras etapas da fase quantitativa, que não estão atribuídas na análise conjunta, serão analisadas por meio da utilização da ferramenta Qualtrics, as respostas foram coletadas considerando os percentuais de respondentes em cada opção do questionário, permitindo assim, observar a relevância de cada item sobre a amostra.

\subsection{Limitações do Estudo}

O foco dado no estudo e que se reflete na coleta de dados e busca do público alvo respondente da pesquisa, se deu no mercado carioca de consumidores de cerveja artesanal, esse foco se fez necessário visto a dificuldade de se alcançar um público nacional durante a pesquisa. Sendo assim, um estudo mais aprofundado do tema com o intuito de estabelecer ações de marketing com abrangência e impactos nacionais se faz necessário em estudos futuros e mais complexos. Considerando ainda essa condição se é importante lembrar que o número de respondentes impacta diretamente no nível 
de confiança e no erro, inerentes ao tamanho da amostra, para estudo mais precisos é importante um alcance maior de respondentes.

O público pretendido tem como característica diversos níveis de envolvimento com o mercado e consumo de cervejas artesanais, o que permite uma maior abrangência para a proposição de ações direcionadas ao mercado consumidor e ao mercado consumidor potencial.

Outro ponto relevante se faz presente na fase de pesquisa qualitativa na qual foram realizadas entrevistas com o intuito de confirmar as variáveis levantadas durante a fase de pesquisa secundária. Pelo seu caráter interativo, o entrevistador passa a ser um elemento de influência sobre o entrevistado, podendo causar constrangimento ou gerar um ambiente incomodo ao respondente pela presença do entrevistador, segundo Marconi e Lakatos (2003). Além do impacto do julgamento do entrevistador sobre as respostas obtidas, ou seja, deve se ter atenção no momento da análise por parte do pesquisador, a fim de, reduzir a tendência da percepção do entrevistador sobre os dados coletados, realizando uma análise imparcial desses dados.

A amostra considerada para o desenvolvimento desse estudo é nãoprobabilístico, que segundo Malhotra (2006), o pesquisador é responsável pelos critérios de definição da amostra impactando na oportunidade de os indivíduos da população terem acesso a entrevista fazendo assim parte da amostra observada. Considerando a população com emprego formal no estado do Rio de Janeiro, segundo o censo IBGE de 2016, onde aproximadamente 7.400.000 pessoas apresentaram alguma ocupação, buscando um nível de confiança de $90 \%$, com uma margem de erro de $10 \%$ o tamanho da amostra necessária para suprir os critérios descrito é de 68 respondente. Sendo assim, esse é o número mínimo de respondentes pretendidos na terceira etapa da pesquisa, que será abordada de forma quantitativa através de questionário, elaborado por meio da ferramenta Qualtrics, disponível através de um link compartilhado pelas redes sociais durante o período entre 01 a 09 de novembro de 2017.

Esses números foram alcançados durante a fase de distribuição da pesquisa chegando a um total de 72 respondentes que concluíram a pesquisa, o número de questionários iniciados foi de 152 respondentes, os questionários iniciados e não concluídos foram excluídos dos dados analisados, a baixa taxa de conclusão pode ser atribuída a complexidade da pesquisa o que impacta diretamente nos resultados alcançados. 


\section{Apresentação e análise dos resultados}

\subsection{Descrição do perfil dos entrevistados}

Para esta primeira parte de análise da pesquisa, foram realizadas quatro entrevistas com atores do setor de cervejas artesanais, com um roteiro de perguntas semiestruturado. Esses atores foram selecionados seguindo a lógica descrita no item 3.2 deste trabalho. Os perfis pretendidos foram conseguidos e serão descritos a seguir. Todos os entrevistados autorizaram a gravação e a divulgação de suas respostas e identidade.

Como a amostra foi selecionada seguindo critérios de seleção baseada na relevância do entrevistado com o universo de cervejas artesanais, o perfil demográfico se mostrou homogêneo, com pouca diferença entre os respondentes, esse fator pode ser atribuído a acessibilidade desses entrevistados por parte do pesquisador.

Nesta etapa, foram entrevistados os seguintes perfis de especialistas do setor: o perfil A sócio de cervejaria com produção cigana, ou seja, não possui fábrica própria, o perfil $\mathrm{B}$, proprietário de fábrica de cervejas que produz o próprio rótulo e para cervejarias ciganas, o perfil $\mathrm{C}$, sócio de uma loja especializada em cervejas artesanais localizada na região da Tijuca e o perfil D, sommelier de cervejas.

O entrevistado que corresponde ao perfil A, foi o sócio da cervejaria carioca Quatro Graus, Marlos da Costa Monçores, 37 anos, eletrotécnico na PETROBRAS e professor de Biofísica no CEDERJ. A Quatro Graus é uma cervejaria cigana e está no mercado há pouco mais um ano, ela já é destaque em diversos eventos e aplicativos de avaliação de cervejas artesanais por parte dos consumidores, como no caso do Untappd ${ }^{5}$.

${ }^{5}$ Untappd é uma rede social virtual que permite que seus usuários realizem checkin em cervejas conforme as bebe, e compartilhar esses check-ins e localizações com amigos. 
O entrevistado que corresponde ao perfil B, foi o sócio da cervejaria Buzzi, de Santa Maria Madalena, região serrana do Rio de Janeiro, Giovani Faria Buzzi, 51 anos, formado em Direito, servidor do Tribunal de Justiça do Estado do Rio de Janeiro, produtor rural de flores e eucaliptos, empresário no ramo de cervejas especiais desde 2013 e que produz para algumas das cervejarias ciganas da região.

O entrevistado que corresponde ao perfil $\mathrm{C}$, foi o sócio da loja especializada em cervejas artesanais, Hopfen Cervejas Especiais, Washington Ferreira Salomão, 36 anos, Analista de Sistemas, que iniciou a sua sociedade na empresa há pouco mais de 1 ano, a loja fica localizada na Av. Maracanã, 727, Tijuca, Rio de Janeiro e opera a mais de 4 anos, sendo uma referência na região.

O entrevistado que corresponde ao perfil D, foi o sommelier da Hopfen Cervejas Especiais, Pedro Henrique, 36 anos, formado em sommelier de cervejas pelo Instituto de Cerveja Brasil, atuante no mercado de cervejas artesanais a mais de 4 anos.

\subsection{Descrição e análise dos resultados do método qualitativo}

$\mathrm{Na}$ etapa qualitativa foi realizada entrevistas com os perfis descritos no tópico anterior, essas entrevistas se deram por meio de um roteiro semiestruturado, que está disponível para consulta no Anexo I deste trabalho. Essa etapa tinha por objetivo validar as variáveis aplicadas na etapa do questionário.

A relevância dos entrevistados para o presente trabalho, se deu pela atuação de cada um deles dentro do mercado de cervejas artesanais e a experiência adquirida de cada um desses perfis e suas diferentes percepções do mercado do qual estão inseridos.

O início de todas as entrevistas foi feito por meio da introdução do motivo do desenvolvimento deste trabalho, bem como a apresentação do objetivo proposto no estudo, já descrito no primeiro capítulo.

A primeira questão contida no roteiro, buscava entender parte do perfil demográfico dos participantes, na questão se desejava saber o nome, a idade e a ocupação de cada respondente. 
De maneira geral os perfis alcançados apresentavam características similares, pois era formado por homens, em idade adulta, com nível superior, que atuam no mercado de trabalho em outras empresas ou outras atividades, além do mercado de cervejas artesanais. Com exceção do perfil $D$, que atua exclusivamente no mercado de cervejas artesanais. A descrição detalhada de cada entrevistado foi abordada no tópico anterior.

Esses dados fazem supor que o mercado de cerveja artesanal, ainda é visto como incerto por parte de seus investidores, que se inserem no mercado, mas ainda exercem outras atividades remuneradas. Esse fato pode estar associado a baixa maturidade do mercado no Brasil e revela o interesse por parte dos empresários em se colocarem neste mercado.

Nas três perguntas seguintes buscou-se entender como se dava a relação atual dos entrevistados com o universo da cerveja artesanal, como esse interesse se iniciou e a quanto tempo estão inseridos no mercado.

Cada entrevistado revelou fazer parte do universo da cerveja artesanal atuando dentro de suas respectivas atividades, o não consumo de cervejas de massa antes de conhecer a cerveja artesanal foi citado pelos perfis $A$ e $D$, de uma maneira geral todos iniciaram no universo das artesanais através da experimentação, ou seja, sendo consumidores, e da busca por adquirir mais conhecimentos sobre este universo. Os perfis $A, B$ e $D$, revelaram ter participado de curso para cervejeiros artesanais caseiros, com atores reconhecidos dentro do universo das artesanais e que ainda ministram os seus cursos para cervejeiros caseiros.

Os perfis apresentaram um tempo de inserção no mercado relativamente pequeno, onde o perfil $A$ iniciou as suas atividades a 1 ano, o perfil $B$ entrou nesse mercado a 4 anos, o perfil $C$ também se inseriu no mercado a pouco mais de 1 ano atrás e o perfil $\mathrm{D}$ está inserido no mercado a 4 anos.

Esses dados sugerem que a experimentação, no cenário nacional é um fator determinante para a iniciação do consumo de cervejas artesanais, bem como, a busca e o interesse por aprofundar o conhecimento desse universo. $O$ consumo da cerveja artesanal não está diretamente associado ao consumo de cerveja de massa. O tempo em que os entrevistados estão inseridos no mercado, sugere a baixa maturidade e o aspecto iniciante que esse mercado apresenta. Ações que promovam o conhecimento do consumidor podem ser uma importante ferramenta de fidelização de clientes.

$\mathrm{Na}$ pergunta seguinte era solicitado ao entrevistado classificar o consumidor de cerveja artesanal, considerando grau de envolvimento, consumo 
e interesse. Essa pergunta tinha por objetivo validar a variável grau de envolvimento.

Para o perfil B, o público é formado por pessoas de maior escolaridade, ou seja, um consumidor mais esclarecido. Para o perfil $D$, se trata de um novo público, de difícil categorização, que sofre a influência do ambiente de consumo. Para o perfil $\mathrm{C}$, o público é formado por 2 nichos diferente, os que já são consumidores e apresentam um maior grau de envolvimento e conhecimento sobre cervejas artesanais e um público em formação, ávido por informações, e muitos desses consumidores estão iniciando no processo de produção caseira. Para o perfil A, o público é curioso e apresenta diferenças regionais, associadas ao nível de maturação do mercado em cada região. De maneira geral todos os perfis entrevistados classificaram o consumidor de cerveja artesanal, como um consumidor curioso, que busca informações e novidades dentro desse mercado.

Segundo as percepções dos respondentes, podemos interpretar que tais características estão intimamente associadas ao ciclo de vida do mercado de cervejas artesanais, que demonstra estar na sua fase de crescimento. É importante ainda destacar que a busca por conhecimento sobre as cervejas artesanais é um importante motivador para o consumo e deve receber atenção das empresas, a fim de, gerar maior associação de suas marcas com o público consumidor.

$\mathrm{Na}$ sexta pergunta, questionou-se aos entrevistados se eles conheciam o seu público alvo.

Segundo o entrevistado do perfil B, conhecer o público alvo é vital para qualquer empreendimento e sendo assim, a busca constante do conhecimento sobre o seu público é essencial. O entrevistado do perfil $A$, revelou buscar sempre informação de seu público consumidor, principalmente por se tratar de um público que consome um produto de nicho, dentro de um mercado de nicho, ou seja, um público mais especializado, o entrevistado citou o aplicativo Untappd, como uma importante ferramenta de interação e coleta de informação sobre o seu público. O entrevistado de perfil C, afirmou não conhecer o seu público alvo, pois sempre se surpreende com o tipo de consumidor que compõe esse público. $O$ entrevistado de perfil $D$, revelou conhecer bem o seu público alvo.

Essas repostas confirmam a importância de estudos voltados para os consumidores de mercados que estão em desenvolvimento. $E$ a falta de informação ou de sedimentação dos perfis de consumo de cervejas artesanais, que pode estar associada a baixa maturidade do mercado. 
Na pergunta seguinte, buscou-se entender como as variáveis preço, sabor, indicação e marca, impactam nos consumidores, segundo a percepção de cada ator desse mercado.

Para o perfil A, o seu público é impactado pela sequência Marca, Preço, Sabor, Indicação, o entrevistado citou ainda a importância da definição de um ponto de venda com o mesmo nível de maturação que o produto e o consumidor. Ele atribui essa característica ao tipo de produto, mais complexo e intenso, que é proposto pela marca Quatro Graus. Para o perfil B, para um consumidor iniciante a sequência considerada é a Marca, Indicação, Sabor e Preço, para um consumidor mais envolvido o Sabor ganha destaque seguido da Indicação, Marca e Preço, o entrevistado destacou ainda que o fator preço só passa a ser relevante com o aumento do consumo em uma única situação de compra. Para o perfil C, o público iniciante é mais impactado pela sequência, Preço, Sabor, Indicação e Marca, já um público mais formado é impactado pela sequência Sabor, Marca, Indicação e Preço. Para o perfil D, o fator sabor é o elemento de maior impacto sobre o consumo, ele destaca ainda que a busca pelo sabor por parte dos clientes, está muito associada ao estilo do momento, ou seja, qual o estilo da "moda", para ele o consumidor é impactado pela sequência Sabor, Indicação, Marca e Preço.

Outro ponto levantado por todos os entrevistados é a busca por novidade, esse conceito é complexo e subjetivo para padronização, principalmente em um mercado iniciante como o das cervejas artesanais, por essa razão essa variável não será explorada na etapa de questionário da pesquisa, porém a sua relevância para os entrevistados merece destaque.

De maneira geral percebemos que cada ator interpreta uma variável diferente para cada público, segundo a observação individual de cada entrevistado sobre o seu consumidor. Isso demonstra a dificuldade de mensurar quais os fatores que o consumidor considera no seu momento de compra. Essas características podem ser associadas ao aspecto iniciante deste mercado, onde tanto o público quanto o mercado passam por momento de desenvolvimento. Essa característica pode ser atribuída também as incertezas de informações sobre os consumidores inerentes a diversos mercados.

$\mathrm{Na}$ penúltima pergunta, foi pedido que o entrevistado desse a sua percepção sobre o mercado de cervejas artesanais no Brasil e no Rio de Janeiro.

Todos os entrevistados se disseram confiantes com o crescimento do mercado, que observam uma nítida evolução tanto do mercado quanto das 
cervejarias brasileiras e cariocas, considerando-se principalmente a qualidade e a inovação, assim como uma notável evolução do público consumidor. Uma barreira importante destacada pelos entrevistados é a questão preço dos produtos, principalmente no cenário de retração econômica atual.

Essas percepções levam a crer que de fato o ciclo de mercado ainda está em sua fase de crescimento. O que torna ainda mais importante a consolidação das marcas e o entendimento do público consumidor por parte dos empresários desse ramo. Além da importância de um adequado posicionamento de marca.

Por fim, foi perguntado sobre qual a informação do público alvo os entrevistados não dispunham e que gostariam de dispor.

Para o perfil $B$, informações como escolaridade e poder aquisitivo são as informações mais relevantes. O perfil $A$, descreveu que busca estar em contato com o seu público através de aplicativos, eventos e redes sociais e que o feedback de seus consumidores é extremamente relevante para o aperfeiçoamento do produto. Para o perfil $\mathrm{C}$, a quantidade de dinheiro que 0 cliente está disposto a investir no consumo de cervejas artesanais é o fator mais relevante, pois permite um melhor direcionamento da venda, considerando as expectativas do cliente. $O$ perfil $D$, não soube informar nenhuma variável de interesse, devido a variabilidade de perfis de consumidores.

É possível supor que informação é uma carência nesse mercado e que desenvolver estudos que possam auxiliar os empresários nas suas tomadas de decisões é relevante para o cenário atual, principalmente ao considerarmos o crescimento que esse mercado vem experimentando nos últimos anos e suas projeções para o futuro.

\subsection{Descrição do perfil dos respondentes do questionário}

$\mathrm{Na}$ etapa quantitativa do estudo, que se deu por meio de distribuição de questionário, através da plataforma Qualtrics, de maneira online por meio de redes sociais e link contendo o questionário, enviado através de aplicativos de envio de mensagens, como o software de mensagens instantâneas Whatsapp, foram alcançados 72 respondentes anônimos. Esse número compõe a amostra analisada neste trabalho.

Nesta etapa se buscou diferentes perfis de consumidores, tanto considerando a sua diversidade demográfica quanto o seu envolvimento com o 
universo das cervejas artesanais, buscando uma maior diversidade de fontes de informação.

A amostra alcançada teve como perfil aproximadamente $71 \%$ dos respondentes do sexo masculino, 85\% dos respondentes estão entre 18 e 39 anos, as principais classes sociais atingidas foram a C e a D e mais de $97 \%$ dos respondentes possuem nível de escolaridade superior incompleto ou superior completo.

\subsection{Descrição e análise dos resultados do método quantitativo}

O questionário foi desenvolvido com um número total de 10 questões. Nas questões 1 e 2 se buscou medir o grau de envolvimento/consumo do respondente, a questão 3 foi elaborada para a aplicação de análise conjunta, onde se buscou testar quais os fatores mais relevantes para os consumidores dentre diferentes combinações de fatores e níveis, simulando opções reais do mercado, as questões 4, 5 e 6 foram elaboradas com o intuito de se medir 3 diferentes cenários de compra e a mudança de valor de cada variável de acordo com o cenário proposto, as questões $7,8,9$ e 10 são questões que ajudam a compor o perfil demográfico da amostra.

Esta parte da seção é referente a dados demográficos que são importantes para analisar o nível de heterogeneidade da amostra. Eles foram colocados por último, porque são dados onde acredita-se que os respondentes não necessitam de muito esforço cognitivo para responder, já que se esperar um menor nível de atenção nesta fase do questionário.

Os dados coletados foram transformados em gráficos para facilitar a interpretação por parte do leitor.

Quanto a questão 7 que se referia ao gênero do respondente, os resultados obtidos seguem na figura abaixo: 


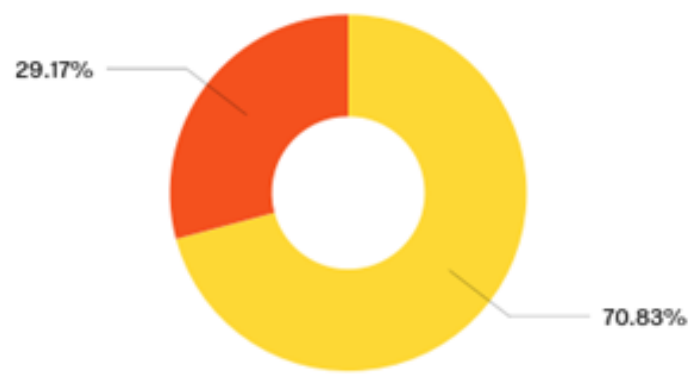

Figura 1 - Gráfico gênero - Fonte: Autor.

Temos que, aproximadamente $71 \%$ dos respondentes pertencem ao gênero masculino. Essa proporção levar a crer que, o universo de consumo de cervejas artesanais é concentrado no gênero masculino. Essa informação aponta para a necessidade de ações que promovam o consumo de mulheres nesse mercado, aumentando assim o número de consumidores potenciais do setor. O uso da informação junto ao público feminino, bem como uma proposta de atendimento customizado para essa população, pode ser um importante atrativo ao consumo.

Empresas que buscarem esse posicionamento podem melhorar a posição da imagem da empresa na mente deste púbico alvo, ao considerarmos Kotler e Keller (2000).

$\mathrm{Na}$ pergunta seguinte era abordado a faixa etária dos respondentes, os resultados obtidos seguem na figura abaixo:

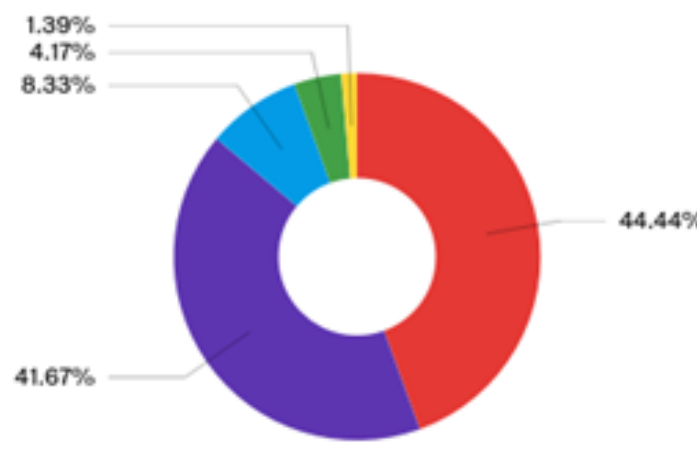


O gráfico nos mostra que aproximadamente $86 \%$ dos respondentes é formada pessoas em idade adulta, com a idade variando entre 18 e 39 anos.

Esses dados sugerem que o mercado tem mais impacto nas novas gerações. Essa informação é importante, pois permite às empresas adequarem a sua linguagem para o público alvo pretendido.

A pergunta 9 buscava medir o nível de formação da amostra, os dados obtidos podem ser vistos na figura abaixo:

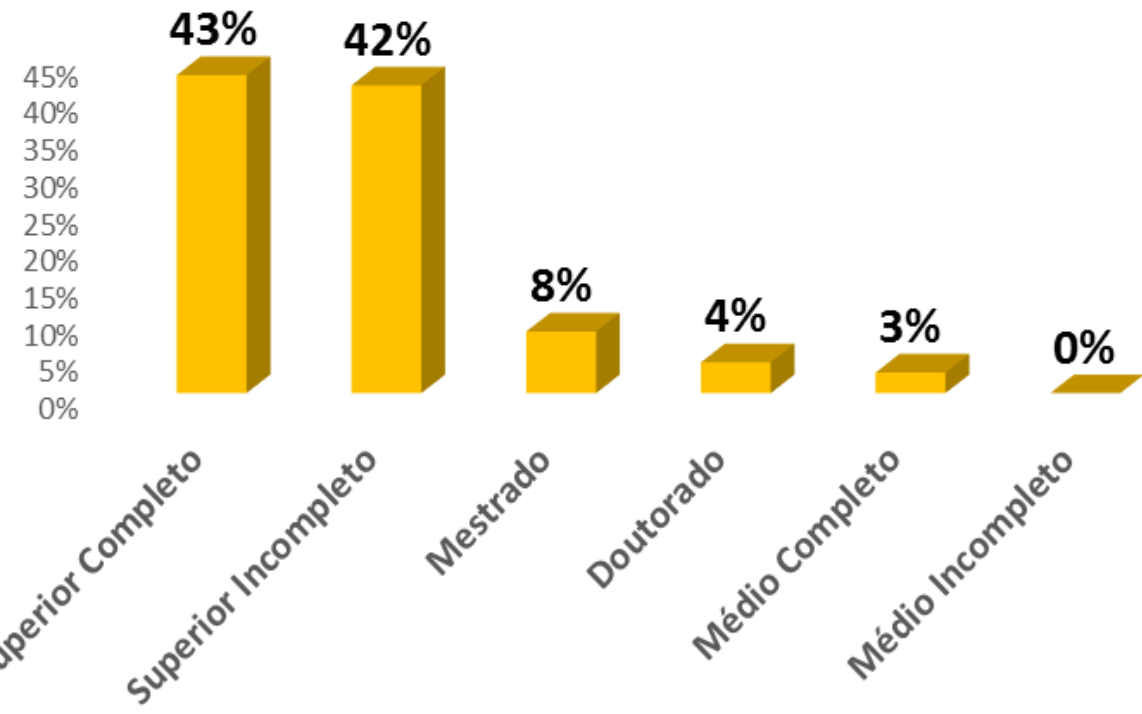

Figura 3 - Gráfico formação acadêmica - Fonte: Autor.

O gráfico nos revela que apenas $2,78 \%$ da amostra não possui ou iniciou algum tipo de formação superior.

Os dados sugerem que o público consumidor de cervejas artesanais é formado por indivíduos com maior nível de instrução. Assim como a faixa etária, esse dado tem alto grau de relevância para a adequação da comunicação e proposta das empresas junto ao seu público alvo.

$\mathrm{Na}$ última pergunta do questionário era abordada a classe social do respondente, para a definições das classes sociais foi considerado o critério de faixas de salário-mínimo do IBGE, os resultados obtidos nessa questão seguem na figura abaixo: 


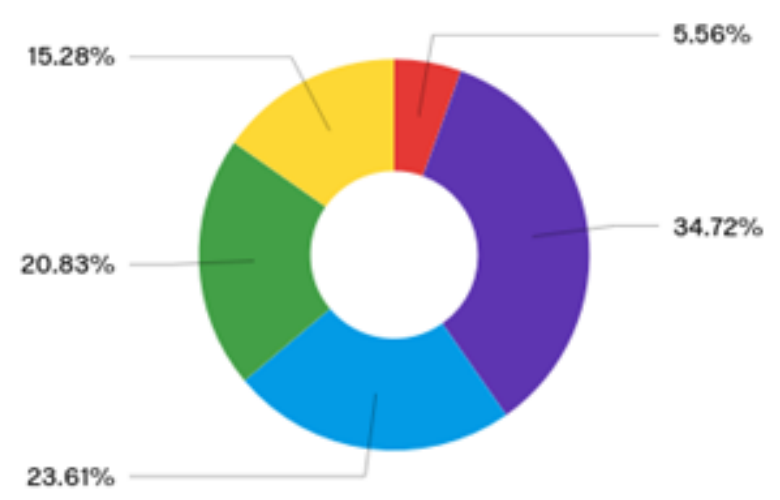

Até R\$1.874,00

Entre $R \$ 1,875,00$ a $R \$ 4.685,00$

Entre R\$ $4.686,00$ a $R \$ 9.370,00$

Entre $R \$ 9.371,00$ a $R \$ 18.740,00$

Acima de $\mathrm{R} \$ 18.741,00$

Figura 4 - Gráfico classe social - Fonte: Autor.

O gráfico nos revela que na amostra alcançada a classe $D$, foi a mais representada, porém a classe $\mathrm{C}, \mathrm{B}$ e $\mathrm{A}$ são respectivamente as próximas classes sociais mais representadas, apesar na maior frequência em $D$, os dados apresentam uma certa proximidade, considerando a realidade do Brasil, podemos considerar que a amostra é representativa para as proporções de representação das classes sociais.

Esse dado sugere que a cerveja artesanal já rompe a barreira das classes e é consumida por todas as classes sociais. Essa informação é relevante pois, indica que a cerveja artesanal tem a capacidade de gerar valor junto ao consumidor de diferentes classes sociais, porém esses dados merecem maior atenção em estudos futuros com uma amostra mais significativa, já que 0 número reduzido da amostra analisada no presente estudo pode possuir algum viés causado pela acessibilidade.

Se considerarmos o consumo de cerveja artesanal como um consumo gerador de status, podemos associar o conceito de Aaker (1998) de brand equity, uma vez que os dados levam a crer que a cerveja artesanal tem apresentado sucesso em criar valor na mente do consumidor, influenciando diretamente no seu consumo neste nicho, independente de qual classe 0 consumidor faz parte.

Nas questões 1 e 2 foi solicitado aos respondentes do questionário que marcassem em uma escala de 0 a 10 , onde 0 significava nenhum envolvimento e 10 muito envolvimento, o seu grau de envolvimento/consumo e o valor gasto 
com cervejas artesanais médio mensal, respectivamente. Os resultados obtidos foram tabulados de maneira cruzada na tabela que se segue:

Tabela 1 - Tabela grau de envolvimento x gasto mensal médio - Fonte: Autor.

\begin{tabular}{|l|c|c|c|c|c|c|c|c|c|c|c|c|}
\hline $\begin{array}{l}\text { Grau de envolvimento/ } \\
\text { RS més }\end{array}$ & 0 & 1 & 2 & 3 & 4 & 5 & 6 & 7 & 8 & 9 & 10 & Total \\
\hline De RS 0,00 a RS 50,00 & 4 & 3 & 2 & 8 & 4 & 3 & 5 & 6 & 2 & 0 & 1 & 38 \\
\hline De RS 51,00 a RS 100.00 & 0 & 0 & 0 & 1 & 0 & 5 & 2 & 5 & 1 & 2 & 3 & 19 \\
\hline De RS 101,00 a RS 150,00 & 0 & 0 & 0 & 0 & 2 & 1 & 0 & 1 & 1 & 1 & 3 & 9 \\
\hline De RS 151,00 a RS 200,00 & 0 & 0 & 0 & 0 & 0 & 0 & 0 & 0 & 2 & 0 & 0 & 2 \\
\hline Mais de RS 201,00 & 0 & 0 & 0 & 0 & 0 & 0 & 0 & 0 & 1 & 0 & 3 & 4 \\
\hline Total & 4 & 3 & 2 & 9 & 6 & 9 & 7 & 12 & 7 & 3 & 10 & 72 \\
\hline
\end{tabular}

$\mathrm{Na}$ tabela podemos notar que o gasto mensal médio entre $R \$ 0,00$ a $R \$$ 50,00 , teve um maior número de respondentes, com praticamente todos os graus de envolvimento contemplados nessa faixa de consumo. Esse dado faz supor, que o consumo mensal de cervejas artesanais, ainda é muito pequeno no cotidiano das pessoas. Esses dados podem estar associados ao momento econômico que o país vem enfrentando nos últimos anos, principalmente se considerarmos o consumo de bebidas alcóolicas como um item supérfluo no consumo da população.

A fim de melhorar a percepção da representatividade do grau de envolvimento com o valor gasto, foi elaborada a tabela que se segue, com os percentuais de cada respondente, considerando o número de resposta no determinado grau de envolvimento sobre o total de respostas da faixa de gasto mensal.

Foram considerados todos os graus de envolvimento nesta etapa de análise, pois ainda que um consumidor tenha baixo grau de envolvimento com o mercado de cerveja artesanal, esta respondente é um consumidor em potencial, seja pela mudança no próprio consumo, seja ao comprar uma cerveja artesanal para presentear alguém próximo ou pelo consumo em grupo.

Tabela 4 - Tabela grau de envolvimento x gasto mensal médio (\%) - Fonte: Autor.

\begin{tabular}{|l|c|c|c|c|c|c|c|c|c|c|c|c|}
\hline $\begin{array}{l}\text { Grau de envolvimento / } \\
\mathrm{R} \$ \text { mês }\end{array}$ & 0 & 1 & 2 & 3 & 4 & 5 & 6 & 7 & 8 & 9 & 10 & Total \\
\hline De $\mathrm{R} \$ 0,00$ a $\mathrm{R} \$ 50,00$ & $11 \%$ & $8 \%$ & $5 \%$ & $21 \%$ & $11 \%$ & $8 \%$ & $13 \%$ & $16 \%$ & $5 \%$ & $0 \%$ & $3 \%$ & $100 \%$ \\
\hline $\mathrm{De} \mathrm{R} \$ 51,00$ a $\mathrm{R} \$ 100.00$ & $0 \%$ & $0 \%$ & $0 \%$ & $5 \%$ & $0 \%$ & $26 \%$ & $11 \%$ & $26 \%$ & $5 \%$ & $11 \%$ & $16 \%$ & $100 \%$ \\
\hline De $\mathrm{R} \$ 101,00$ a $\mathrm{R} \$ 150,00$ & $0 \%$ & $0 \%$ & $0 \%$ & $0 \%$ & $22 \%$ & $11 \%$ & $0 \%$ & $11 \%$ & $11 \%$ & $11 \%$ & $33 \%$ & $100 \%$ \\
\hline De $\mathrm{R} \$ 151,00$ a $\mathrm{R} \$ 200,00$ & $0 \%$ & $0 \%$ & $0 \%$ & $0 \%$ & $0 \%$ & $0 \%$ & $0 \%$ & $0 \%$ & $100 \%$ & $0 \%$ & $0 \%$ & $100 \%$ \\
\hline Mais de $\mathrm{R} \$ 201,00$ & $0 \%$ & $0 \%$ & $0 \%$ & $0 \%$ & $0 \%$ & $0 \%$ & $0 \%$ & $0 \%$ & $25 \%$ & $0 \%$ & $75 \%$ & $100 \%$ \\
\hline
\end{tabular}

Podemos notar que nas faixas de gasto mensal maior que $R \$ 50,00$ existe uma maior concentração dos respondentes nos graus de envolvimento maior que 5, que é o ponto médio dessa escala. Esse dado sugere que quanto 
maior o grau de envolvimento maior o gasto com cerveja artesanal pelo consumidor e que o fator preço é determinante em todas as faixas de envolvimento, para um cliente com maior sensibilidade a este fator.

A questão 3 , foi elaborada para a aplicação de análise conjunta, onde se buscou testar quais os fatores mais relevantes para os consumidores dentre diferentes combinações de fatores e níveis, simulando opções reais do mercado

Os dados dessa questão foram coletados e ordenados segundo o grau de envolvimento, permitindo a tabulação dos dados da análise conjunta, considerando além das preferências de escolha dos cartões, o grau de envolvimento e consumo dos respondentes. Para uma melhor dinâmica do questionário, foi solicitado aos respondentes que ordenassem os cartões de 1 a 12, considerando o número 1 como a melhor opção de cartão e com o número 12 a pior opção entre os cartões. Porém na etapa de demonstração e análise de resultados se fez necessário ordenar de maneira inversa as respostas, a fim de, melhorar a exibição desses dados, dessa maneira o item com maior peso ou importância segundo os dados obtidos é aquele que apresenta maior valor numérico. Os dados foram ainda trazidos para uma unidade escalar, com o objetivo de facilitar a comparação entres as informações obtidas.

Dessa maneira foi possível desenvolver gráficos com os dados totais da pesquisa, além de gráficos que consideram diferentes graus de envolvimento, aumentando assim o entendimento da tomada de decisão de cada perfil de consumidor.

$\mathrm{Na}$ figura a seguir, temos o gráfico que compara os níveis preferidos de cada fator de todos os respondentes, sem considerar o grau de envolvimento:

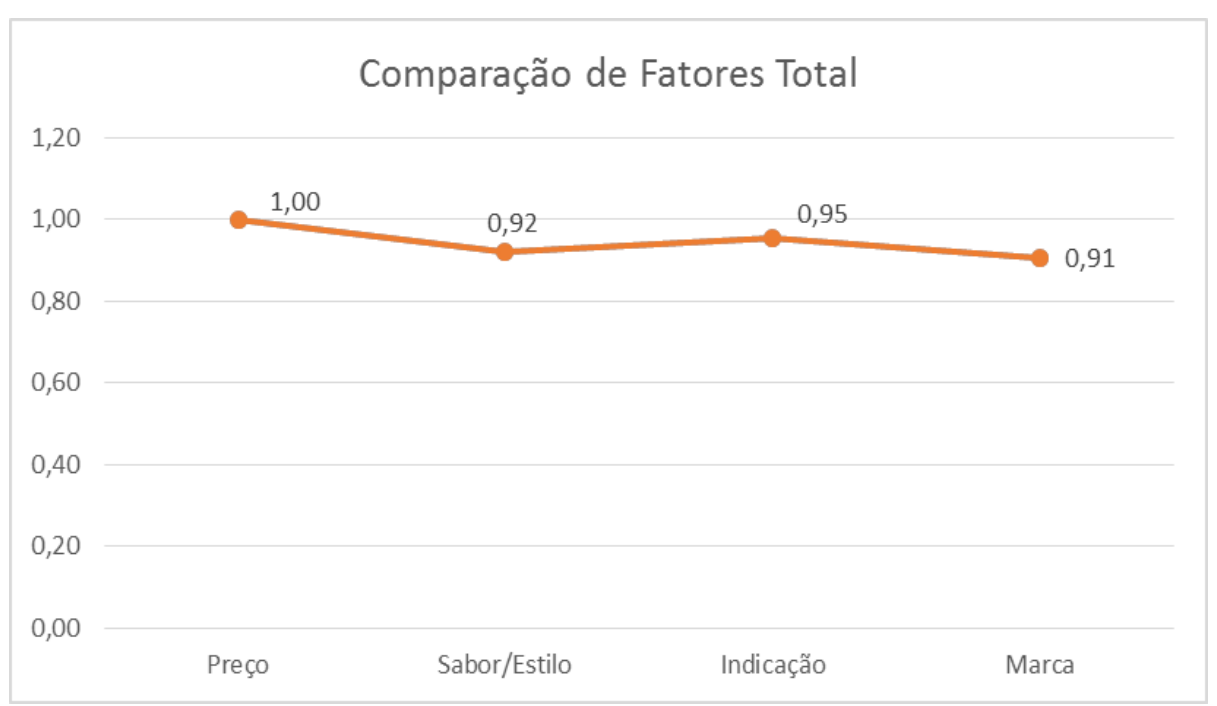

Figura 5 - Gráfico comparação de fatores - Fonte: Autor. 
O gráfico nos mostra a melhor opção de nível de cada fator, para a comparação entre os fatores mais importante para amostra obtida.

Os dados sugerem que o preço é o fator mais importante, seguido da indicação, do sabor/estilo e por último a marca, considerando todos os respondentes. Esses dados sugerem que o mercado no Rio de Janeiro, ainda é muito sensível ao custo de produção das cervejas artesanais, que têm o seu preço final bastante elevado.

Esses dados ainda foram tabulados considerando o grau de envolvimento dos consumidores e os resultados obtidos seguem nas 3 figuras abaixo, respeitando a seguinte interação, fatores $x$ grau de envolvimento, para um grau de envolvimento $<5$, para um grau de envolvimento $=5$ e para um grau de envolvimento $>5$ :

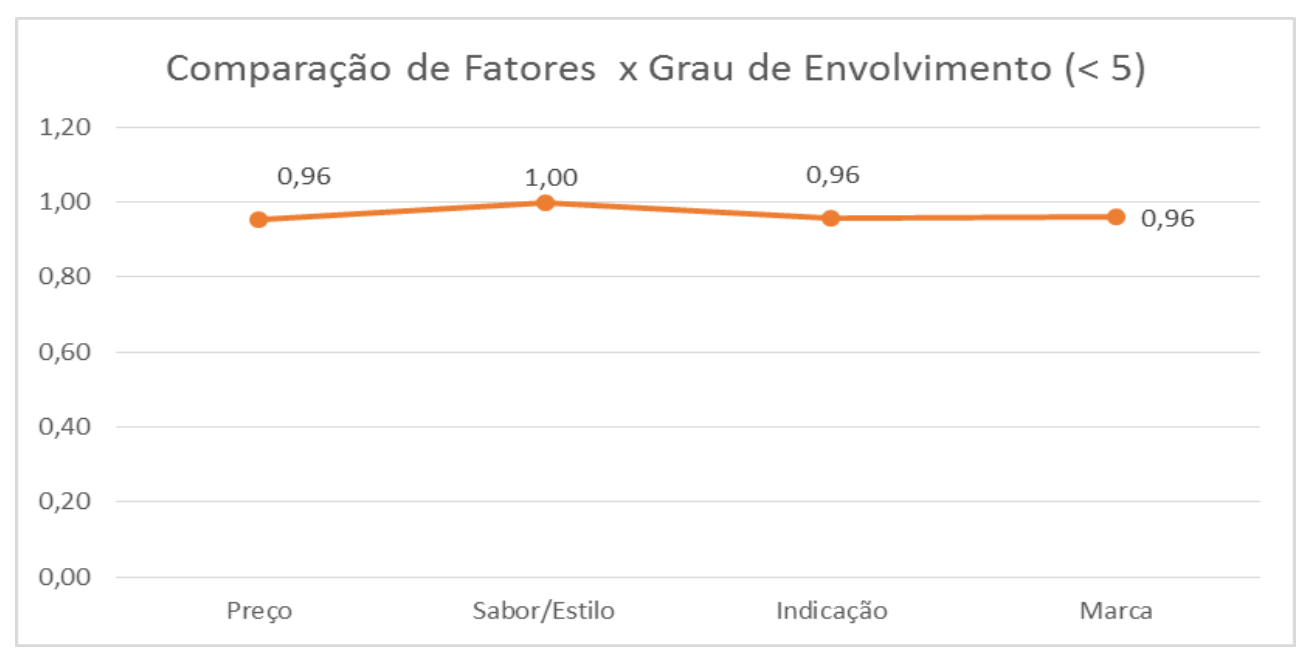

Figura 6 - Comparação de fatores x grau de envolvimento $(<5)$ - Fonte: Autor.

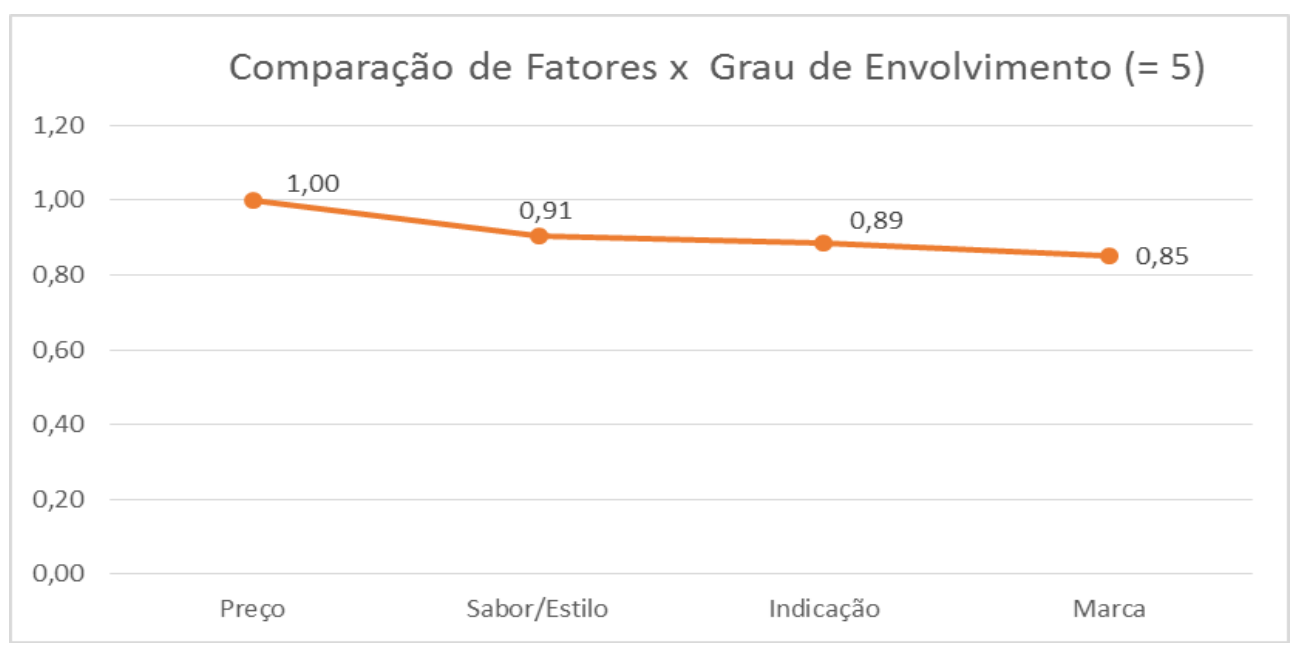

Figura 7 - Comparação de fatores x grau de envolvimento (=5) - Fonte: Autor. 


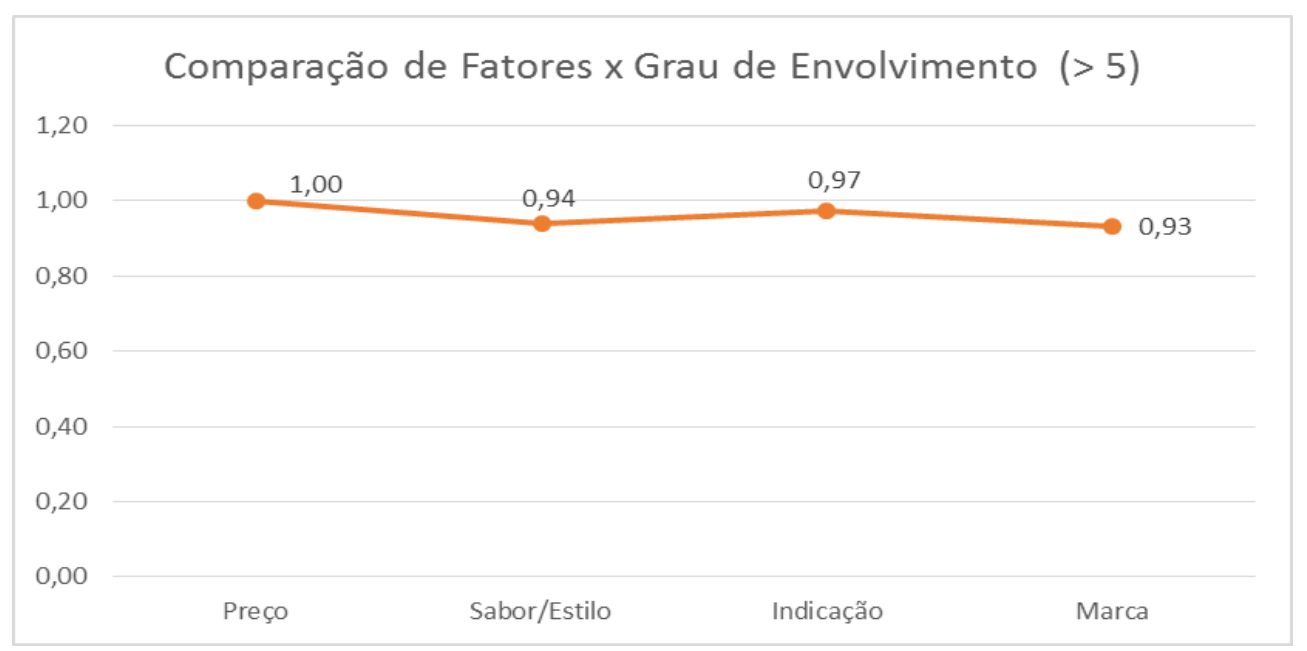

Figura 8 - Comparação de fatores x grau de envolvimento (>5) - Fonte:

Autor.

Os gráficos sugerem que assim como no valor mensal gasto, o grau de envolvimento também exerce mudança na percepção dos atributos do produto.

Sendo assim, o fator mais importante para o consumido com baixo envolvimento $(<5)$ é o sabor/estilo, os demais fatores não apresentaram significância de preferência para esse perfil de consumidor, isso é entendido pelo mercado e descrito pelo perfil D. Durante a entrevista, os perfis B e C atribuíram esse posicionamento ao consumidor de maior envolvimento.

Para o consumidor de envolvimento médio $(=5)$, o fator preço é o mais importante, seguido pelo sabor/estilo, da indicação e da marca.

Para o consumidor de maior envolvimento $(>5)$ o preço também aparece como o fator mais importante, mas nessa faixa de envolvimento a indicação é considerada mais importante que o sabor, sendo a marca o fator menos importante. Esse resultado de certo modo era esperado, já que o consumidor de maior envolvimento está disposto a investir maiores quantidades de dinheiro no seu consumo, além de terem maior grau de informação acerca dos produtos disponíveis escolhendo de maneira direcionada, onde aplicar o seu dinheiro, outro ponto é a busca por novidades o que confirma a segunda posição da indicação na preferência desse perfil.

Podemos notar que o fator marca não recebeu um elevado grau de importância em nenhum dos perfis, esse fator sugere mais de uma possibilidade, atribuição a característica de experimentação do mercado ou a falta de um branding adequado, por parte das empresas, como define Aaker (1996). 
Outro ponto importante do processo de tomada de decisão destacado por Solomon (2011), diz respeito ao quanto um consumidor pesquisa por um produto, de maneira geral indivíduos com baixo ou alto nível de conhecimento sobre o produto tendem a pesquisar menos quando comparados aos indivíduos que apresentam um moderado nível de conhecimento sobre o produto, isso se observa nos perfis extremos, onde a indicação ocupa a segunda posição na preferência dos respondentes.

Apesar dos dados terem sidos tratados em termos de médias, o tamanho da amostra para os diferentes graus de envolvimento ainda é pequeno para representar o todo do universo de consumidores, porém os dados apresentados indicam uma relação que merece ser aprofundada em estudos futuros.

Os dados permitiram ainda a interpretação dos níveis de cada fator e a preferência destes níveis por parte dos respondentes.

Nas figuras que se seguem, teremos os gráficos comparativos entre os níveis de cada fator estudado, esses dados consideram todas as respostas recolhidas com o questionário:

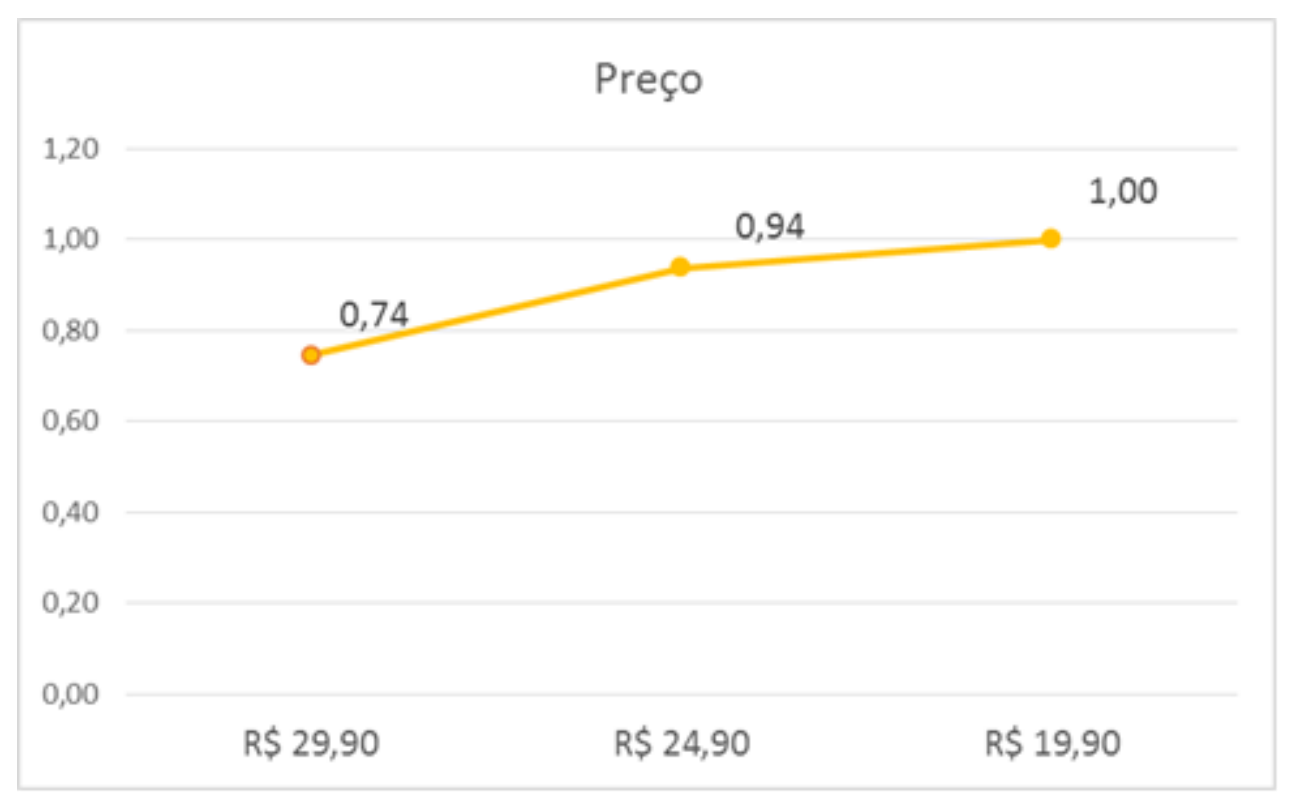

Figura 9 - Gráfico fator preço - Fonte: Autor. 


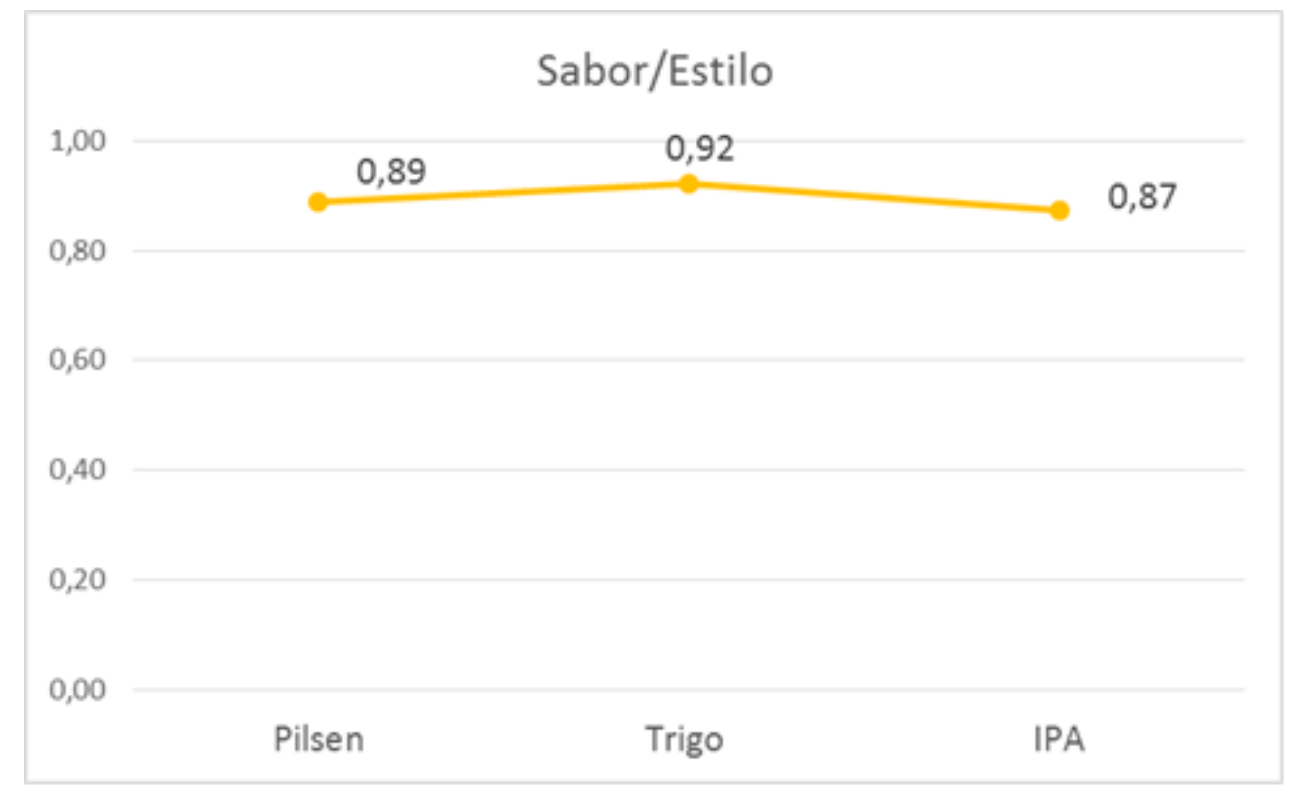

Figura 4 - Gráfico fator sabor/estilo - Fonte: Autor.

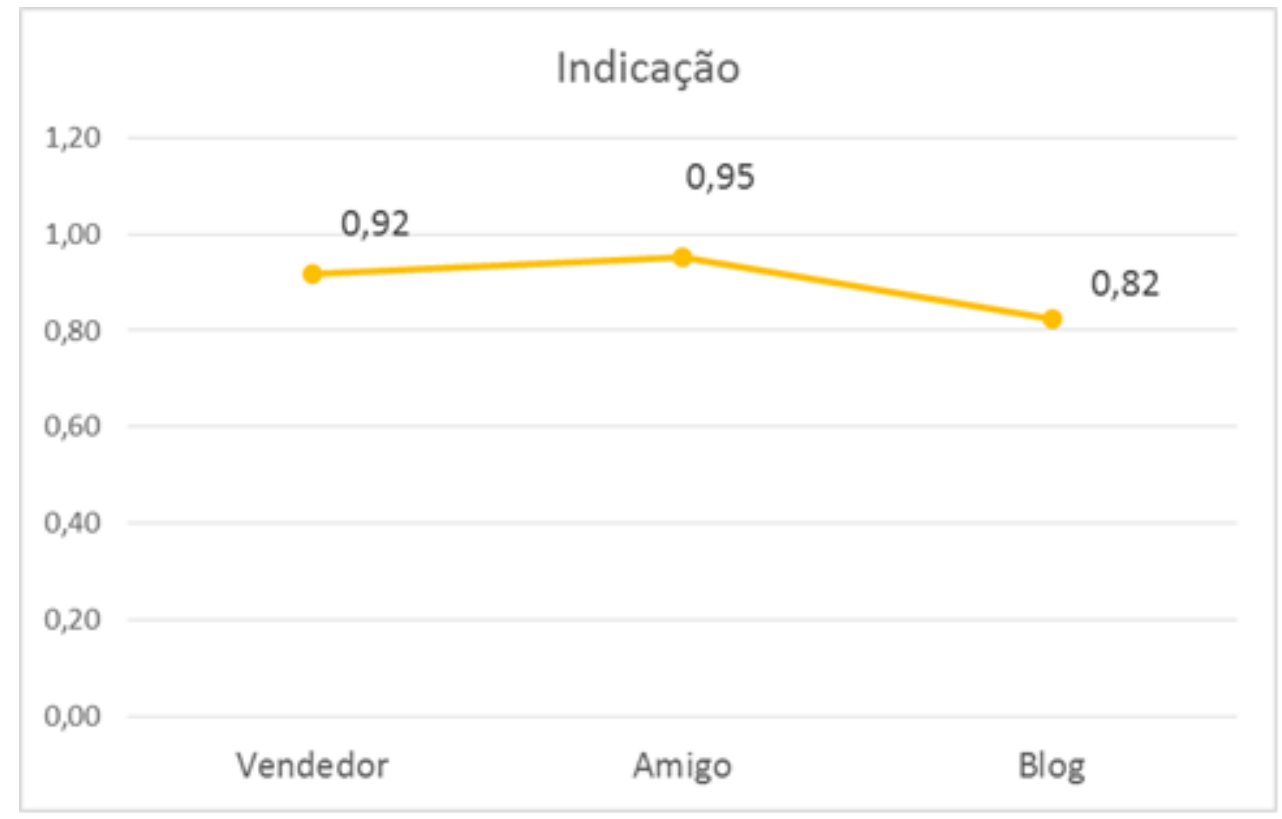

Figura 5 - Gráfico fator indicação - Fonte: Autor. 


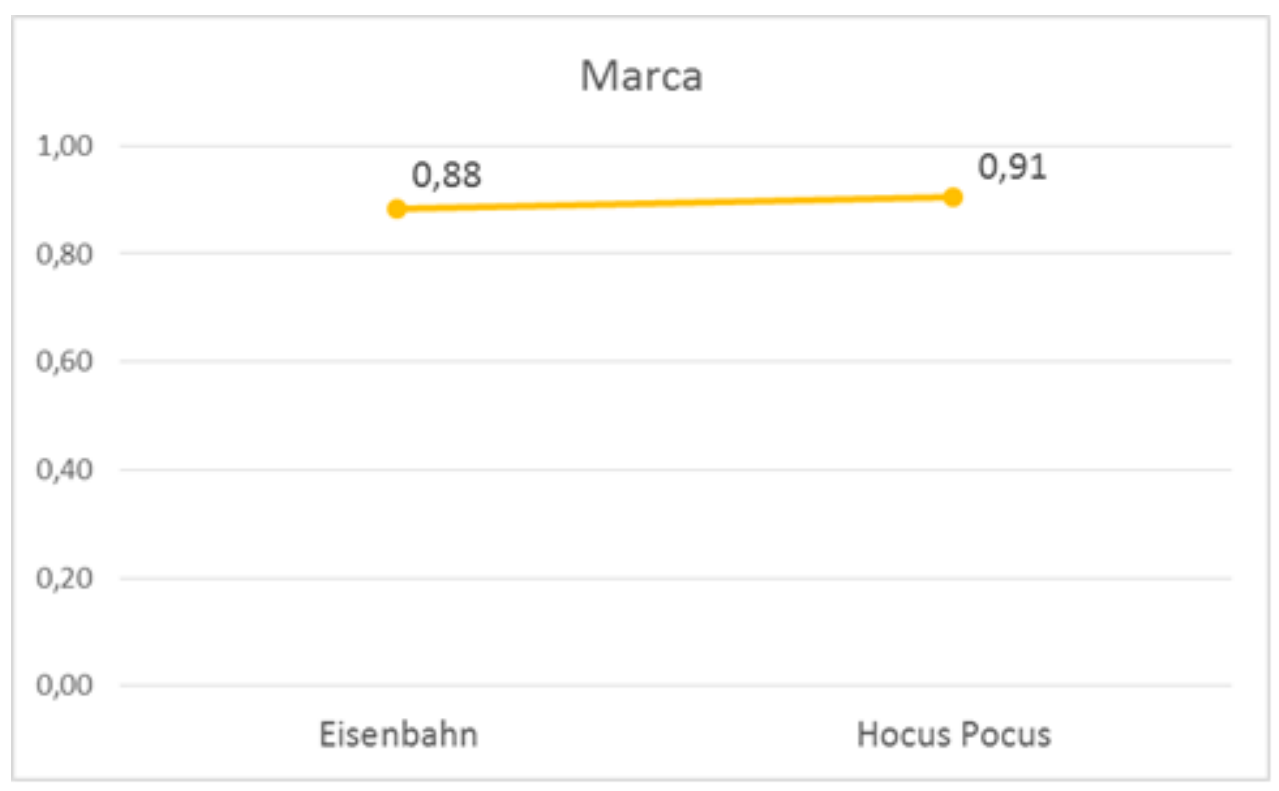

Figura 6 - Gráfico fator marca - Fonte: Autor.

Considerando os 4 fatores estudados podemos notar que o fator preço teve o nível preferido descrito na opção $R \$ 19,90$, isso reflete a preferência por preços menores, além de retomar o baixo valor mensal gasto pela amostra, no fator sabor/estilo o nível de preferência foi a opção trigo, no fator indicação, podemos notar que as indicações realizadas por individuo próximo ao consumidor, como um amigo, apresenta maior impacto obre a escolha dos respondentes e no fator marca, a Hocus Pocus, que apresenta maior identificação com o movimento artesanal teve a preferência dos respondentes.

Dessa forma podemos determinar que o cartão preferido dos respondentes, ou seja, os fatores que geraram maior preferência ao consumo, o preço de $R \$ 19,90$, o sabor/estilo trigo, a indicação de um amigo e a marca a Hocus Pocus, receberam a preferência de escolha da amostra. Esses dados analisados associados aos diferentes perfis de envolvimento permitem traçar paralelos de preferências de consumo para o público alvo.

Nas questões 4, 5 e 6 do questionário, foi solicitado aos respondentes que ordenassem as opções das variáveis: preço, sabor, indicação, rótulo (aspecto visual) e disponibilidade (presença da cerveja no ponto de venda), segundo a sua preferência, onde na primeira posição seria ordenada a variável mais importante e na última posição a variável menos importante, em diferentes cenários de consumo.

A pergunta tinha por objetivo entender se existe diferenças significativas na tomada de decisão de compra, por parte dos consumidores, em diferentes 
cenários. Os cenários descritos foram: o cenário de opção de compra de cerveja para presentear um amigo, o cenário de opção de compra para consumir a cerveja em casa e o cenário de opção de compra onde a cerveja será consumida em bares/restaurantes.

Os resultados dos 3 cenários são demonstrados nas 3 figuras que se seguem:

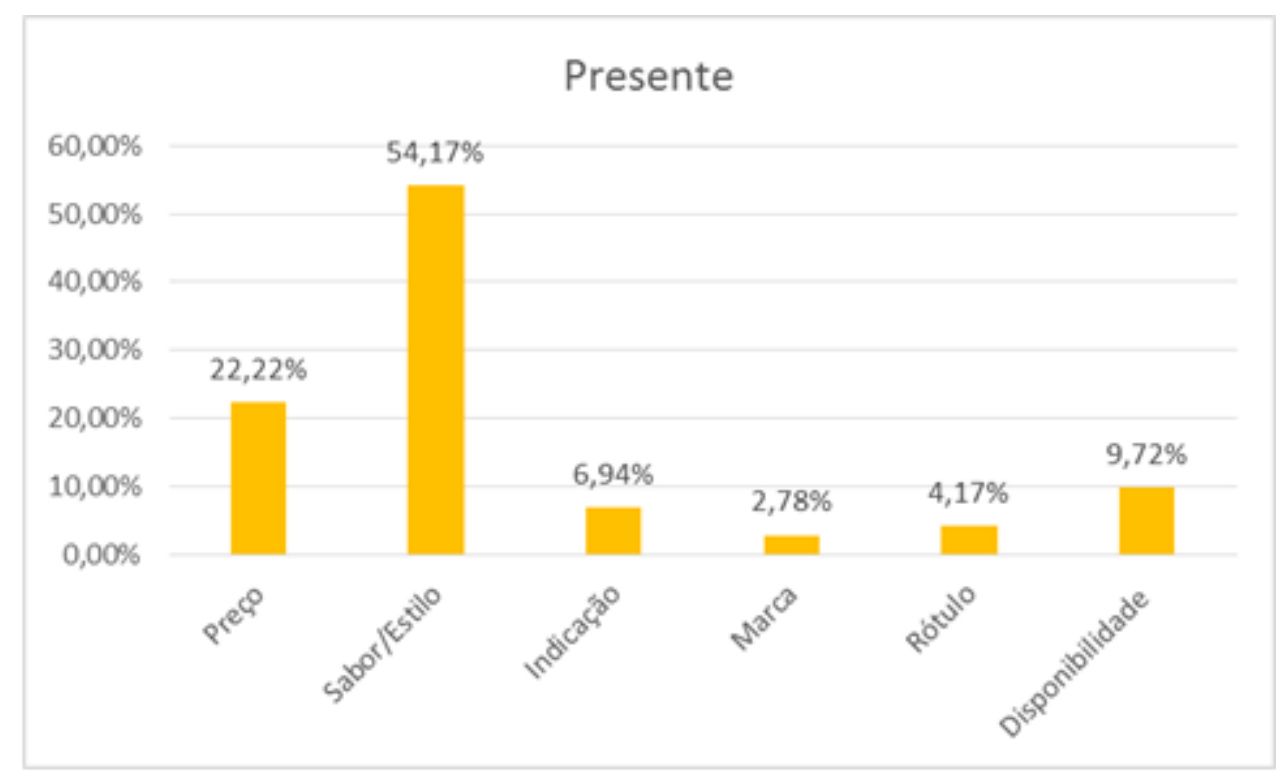

Figura 7 - Gráfico cenário opção de compra para presente Fonte: Autor.

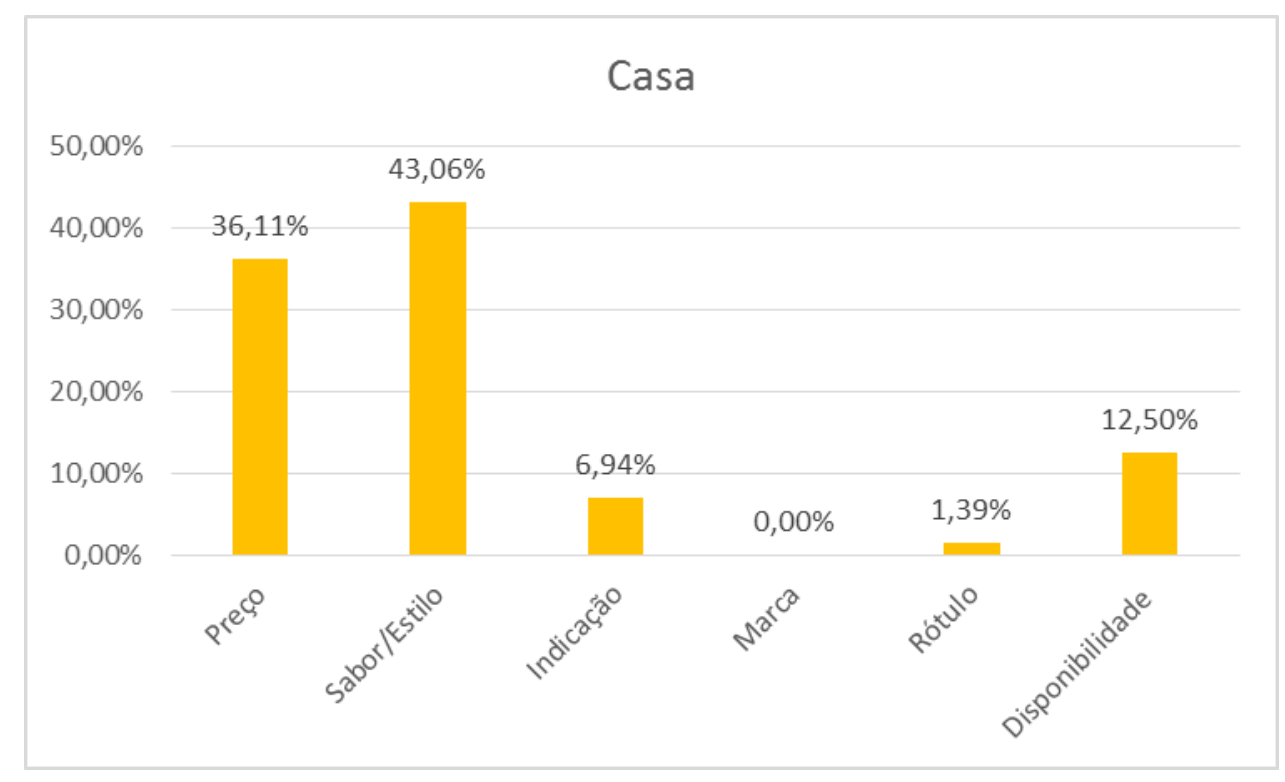

Figura 8 - Gráfico cenário opção de compra para consumo em casa - Fonte: Autor. 


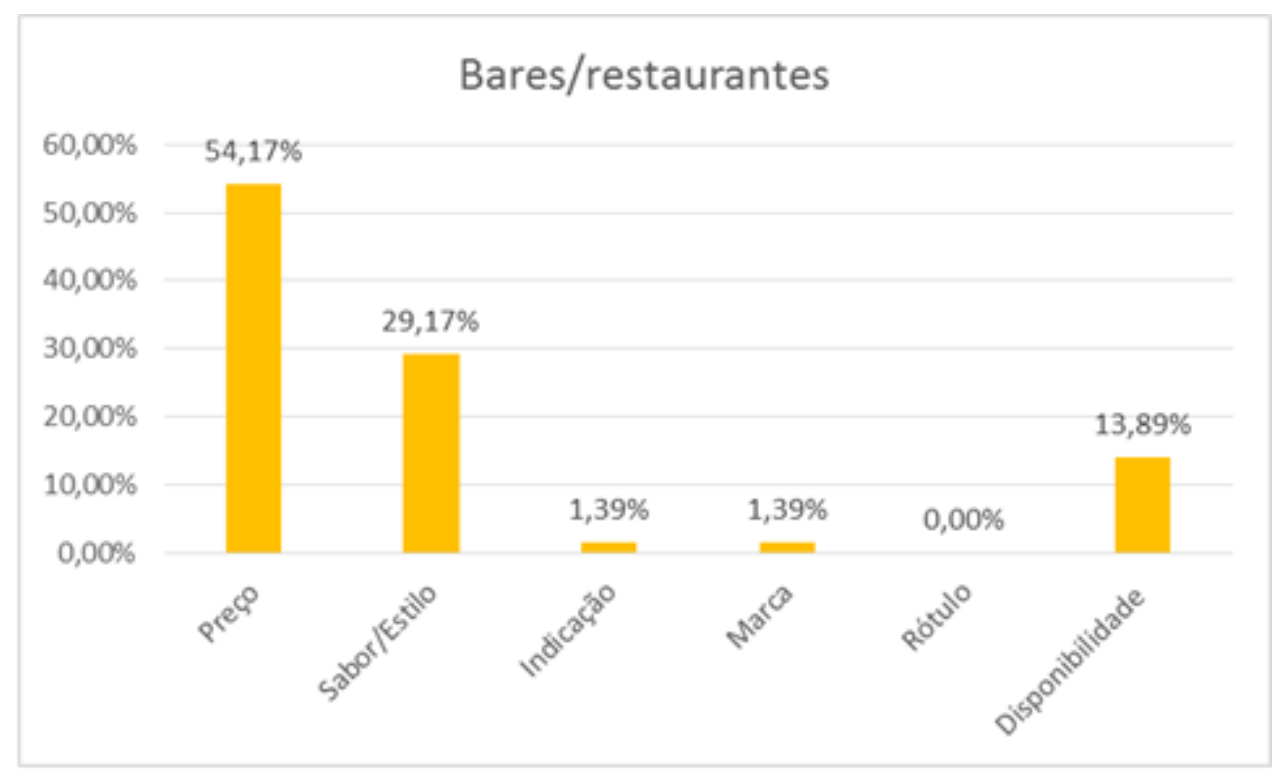

Figura 9 - Gráfico cenário de compra para consumo em bares/restaurantes - Fonte: Autor.

Os gráficos foram tabulados considerando o percentual em que cada variável apareceu como a opção preferida para os respondentes. Podemos notar que no cenário de compra para presente, o fator mais relevante é o sabor/estilo aparecendo $54 \%$ das respostas na primeira posição, seguido do preço, da disponibilidade, da indicação, do rótulo e da marca. Para o cenário de consumo em casa, o sabor/estilo também aparece como a variável mais relevante para $43 \%$ dos respondentes, seguido pelo preço, pela disponibilidade, pela indicação, pelo rótulo, tendo a variável marca não aparecendo na primeira posição em nenhuma das respostas. Para o cenário de consumo em bares/restaurantes a variável preço foi considerada a mais relevantes em $54 \%$ das respostas, seguido do sabor/estilo e da disponibilidade. As vaiáveis indicação e marca apareceram como a melhor opção o mesmo número de vezes. Neste cenário o rótulo não foi escolhido como a opção mais importante em nenhuma das respostas.

De uma maneira geral para todos os cenários, todas as variáveis apresentaram uma relativa importância na tomada de decisão de compra.

Comparando os 3 gráficos podemos notar, que a situação de compra é muito relevante para o consumidor e que em cada situação uma variável tem um peso maior que a sua correspondente em outros cenários.

O entendimento dessas distinções no momento da compra, permite a adaptação das estratégias de vendas para gerar um maior impacto sobre o consumidor, considerando a influência de cada variável. 
Os dados desse estudo sugerem que as variáveis sabor/estilo, preço e disponibilidade de uma maneira geral, são as variáveis mais importantes para o consumidor nos cenários de compra descritos.

Todas essas variáveis são controláveis pelos atores do mercado e devem ser observadas, com o objetivo de traçar métodos de vendas e comunicação com o público alvo.

O posicionamento da variável marca nos diferentes cenários e seu peso observado na etapa de análise conjunta, é uma avaliação que causa surpresa e vai contra a heurística da escolha, (SOLOMON, 2011). Essa interpretação gera reflexão sobre o alcance e a fixação das marcas na mente dos consumidores e indicam o não posicionamento da marca, segundo o que diz, Kotler e Keller (2000). Esse fato pode estar associado a uma falha no posicionamento das marcas, ao cenário de hiperescolha que esse mercado apresenta ou ao caráter iniciante no qual tanto as marcas, quanto o público estão inseridos. De qualquer maneira, é necessário um maior esforço por parte das marcas em aumentarem o seu poder de influência sobre o consumidor, considerando os dados abordados neste trabalho e que refletem a amostra alcançada. 


\section{Conclusões e recomendações para novos estudos}

No primeiro capítulo deste estudo, foi apresentada uma curta contextualização acerca do mercado de cervejas artesanais, sua importância para o mercado brasileiro e suas projeções. Além do cenário mercadológico, foram apresentados os objetivos intermediários, os quais visavam avaliar o grau de envolvimento dos consumidores com a cerveja artesanal, entender a percepção do consumidor sobre o produto e identificar o impacto de cada fator selecionado no processo de compra e sobre o consumidor. O trabalho teve por objetivo determinar quais os fatores que influenciam o processo de tomada de decisão dos consumidores de cervejas artesanais.

O segundo capitulo deste trabalho, contemplou o referencial teórico, que serviu como base e suporte para as questões abordadas ao longo do estudo. $O$ entendimento do posicionamento de marca junto ao público consumidor e a relevância de se fazer presente na mente de seus clientes, complementado pelos conceitos de brand equity, é determinante para compreender o impacto das ações de marketing empregadas pelas empresas, buscando compreender se esses impactos estão sendo positivos ou negativos junto ao público alvo. Os conceitos de tomada de decisão, são extremamente relevantes em um mercado ávido por novidades e que se encontra em fase de crescimento intenso.

Dentro do contexto de desenvolvimento deste trabalho, cabe ressaltar as limitações presentes neste desenvolvimento e que o fazem especifico, mas útil e relevante para a academia e para empresas do setor que desejam se utilizar das informações contidas neste trabalho.

Para se atingir os objetivos propostos por este trabalho, realizou-se uma pesquisa dividida em duas etapas, uma primeira etapa qualitativa e uma segunda etapa quantitativa, na primeira etapa foram entrevistados 4 atores de diferentes perfis do mercado de cervejas artesanais, esta etapa foi bastante proveitosa pela possibilidade de uma maior imersão no mercado, através da experiência e relevância dos entrevistados. A etapa quantitativa se mostrou bastante reveladora, foram alcançados 72 respondentes nesta etapa, com perfis diversificados, o que contribuiu para uma avaliação mais ampla do mercado consumidor de cervejas artesanais. 
Dentre as principais questões levantadas ao logo desse trabalho se destacou, a relevância de se considerar o grau de envolvimento dos entrevistados, o que permitiu uma melhor avaliação dos resultados obtidos, trazendo maior confiança na diferenciação do público atingido.

A etapa de análise conjunta, se mostrou excessivamente complexa para os respondentes, e é válido o registro, pois se trata de uma técnica que gera uma quantidade de dados a serem trabalhados muito extenso e de profundo conhecimento, o impacto da técnica sobre as inferências acerca do tema estudado, é extremamente relevante, trazendo uma maior compreensão por parte do pesquisador sobre as preferências de consumo da amostra que responde de forma extensa e indireta.

De uma maneira geral o estudo, mostrou que o mercado de cerveja artesanal é um mercado iniciante, onde o consumidor tem evoluído junto com o mercado, mostrou ser um mercado de alto envolvimento e geração de valor, com consumidores de alta formação acadêmica, o que permite supor, que se trata de um mercado de maior nível de instrução, esse fato deve ser observado no momento de se gerar comunicação com os clientes.

As informações obtidas nesse estudo demonstram que o foco no cliente é extremamente relevante para a tomada de decisão de compra e que as principais variáveis consideradas pelo consumidor no seu momento de compra, são o sabor/estilo, o preço e a indicação, ou seja, duas características do produto e uma característica de relacionamento com o cliente.

A busca por informação, a curiosidade, a busca por novos sabores, a busca por preços mais acessíveis, parecem ser os principais pontos do cenário atual, no que tange ao consumidor de cervejas artesanais.

Por tanto, ações de marketing voltadas para aumentar o grau de envolvimento dos consumidores são de fato importantes, esse consumidor é extremamente interessado no que está consumindo e nas novidades do setor, o sabor ainda é uma importante variável, assim como o elevado preço praticado no país, muito por conta dos altos custos que mercados iniciantes enfrentam em seu ciclo de vida.

O estudo revelou uma baixa relevância de duas variáveis que merecem um estudo mais aprofundado e uma maior atenção por parte das cervejarias, que é a pouca importância atribuída a marca e ao rótulo, apesar de ser um mercado de hiperescolha com inúmeras opções a falta de relevância da variável marca para a amostra, causa uma certa estranheza, afinal como Al Ries e Jack Trout (1989), definem uma estratégia de posicionamento não necessariamente deve 
estar centralizada no produto, mas sim considerar o posicionamento na mente do consumidor potencial. Ou seja, mudanças realizadas na embalagem, nome ou preço do produto, são mudanças que visam exercer uma posição de valor na mente do público-alvo, o que não altera o produto em si.

Além desta conclusão, é válido esperar que este trabalho possa servir como fonte de consulta para estudos posteriores que abordem o mercado de cervejas artesanais no Brasil, contribuindo para a ampliação do conhecimento a ser gerado, levando em conta as especificidades deste setor que possui cada vez mais importância para a economia brasileira.

\subsection{Sugestões e recomendações para novos estudos}

Como sugestão para novos estudos, fica a recomendação da aplicação do estudo desenvolvido neste trabalho em uma amostra mais representativa do mercado, a fim, de se obter dados mais precisos para o auxílio aos empresários do setor. Assim como, a aplicação em um âmbito nacional, considerando os regionalismos e os diferentes níveis de maturação do mercado em cada região como variáveis importantes no perfil de consumo do público.

A repetição desse estudo, em um horizonte temporal, a fim de, se obter dados comparáveis em tempos distinto, monitorando a evolução desse mercado e público, pode trazer importantes contribuições para o cenário das cervejarias artesanais no Rio de Janeiro e no Brasil. 


\section{Referências Bibliográficas}

AAKER, David. Criando e administrando marcas de sucesso. Tradução Eduardo Lasserre. São Paulo: Futura, 1996.

AAKER, David. Marcas: brand equity gerenciando o valor da marca. Tradução André Andrade. São Paulo: Negócio, 1998.

ANPAD. O Uso da Técnica de Análise Conjunta na Pesquisa em Marketing: uma Avaliação das Publicações Brasileiras Disponível em: <http://www.anpad.org.br/ anpad/eventos.php?cod_evento=1\&cod_edicao_subs ecao $=149 \&$ cod_evento_edicao $=10 \& c o d \_e d i c a o \_t r a b a l h o=5536>$. Acessado em: 25 set. 2017

BRESSIANI, C. Artigo: 'O crescimento de $39,6 \%$ no número de cervejarias em 2016 é espetacular'. O GLOBO. Disponível em: < http://blogs.oglobo.globo.com/aqui-se-bebe/post/artigo-o-crescimento-de-396-nonumero-de-cervejarias-em-2016-e-espetacular.html>. Acesso em: 20 jun. 2017.

CERV BRASIL. Anuário 2016. Disponível em: < http://www.cervbrasil.org.br/paginas/index.php?page=anuario-2015>. Acesso em: 18 jun. 2017.

CRESCITELLI, E.; SHIMP, T. Comunicação de marketing: integrando, propaganda, promoção e outras formas de divulgação. São Paulo: Ceangage Learning, 2012.

Escola superior de cerveja e malte. CERVEJARIA CIGANA Disponível em: <http://cervejaemalte.com.br/blog/cervejaria-cigana/>. Acesso em: 8 nov. 2017.

GLOBORURAL. Tradicional nos EUA, cerveja artesanal vive seu melhor momento no Brasil Disponível em: < http://revistagloborural.globo.com/Noticias/noticia/2016/08/tradicional-nos-euacerveja-artesanal-vive-seu-melhor-momento-no-brasil.html>. Acesso em: 29 out. 2017.

IBGE. População no último censo. Disponível em: < https://cidades.ibge.gov.br/brasil/rj/panorama > Acesso em: 28 set. 2017.

INSTITUTO DA CERVEJA BRASIL. Infográfico - Mercado Brasileiro de Cervejarias Artesanais.

Disponível em: 
https://www.institutodacerveja.com.br/blog/n114/novidades/infografico-mercadobrasileiro-de-cervejarias-artesanais>. Acesso em: 17 Jun. 2017.

KOTLER, P. Administração de Marketing. 10ạ Edição. São Paulo: Prentice Hall, 2000.

KOTLER, P.; KELLER, K. L. Administração de Marketing.12.ed. São Paulo: Pearson Prentice Hall, 2006.

KOTLER, PHILIP. (2009). Marketing para o Século XXI. ed. Ediouro: São Paulo.

KOTLER, Philip. ARMSTRONG, G. Princípios de marketing. 9.ed. São Paulo: Prentice Hall, 2003.

MALHOTRA, N. Pesquisa de marketing: uma orientação aplicada. 3.ed. Porto Alegre: Bookman, 2001.

MARCONI, Marina de Andrade; LAKATOS, Eva Maria Fundamentos de metodologia científica 1. - 5. ed. - São Paulo: Atlas 2003.

RIES, Al; TROUT Jack. Marketing de guerra 2. São Paulo: MacGraw-Hill, 1989.

SEBRAE. Relatório de inteligência, Alimentos, Cerveja Artesanal Disponível em:

https://www.sebraeinteligenciasetorial.com.br/produtos/relatorios-de-

inteligencia/cervejas-artesanais/55c4ad3614d0c01d007ffeae >. Acesso em: 15 jun. 2017.

SOLOMON, Michael R. O Comportamento do Consumidor, 9. ed., Porto Alegre, ARTMED, 2011.

TRIVIÑOS, Augusto Nibaldo Silva, - Introdução à pesquisa em ciências sociais: a pesquisa qualitativa em educação - São Paulo: Atlas, 1987. 


\section{Anexo 1 - Roteiro das entrevistas - Fonte: Autor.}

Roteiro da entrevista.

Olá, sou formando em administração de empresas pela PUC-Rio e estou desenvolvendo uma pesquisa com o objetivo de entender quais são os fatores que influenciam o processo de tomada de decisão dos consumidores de cervejas artesanais. E gostaria de realizar algumas perguntas com especialistas e varejistas desse mercado. Desde já agradeço a sua participação.

1- Qual o seu nome, idade e ocupação?

2- Qual a sua relação com o universo da cerveja artesanal?

3- Como você conheceu e porque se interessou sobre esse nicho?

4- A quanto tempo você se dedica a esse mercado?

5- Como você classificaria o consumidor de cerveja artesanal? (Considerando o grau de envolvimento/consumo/interesse)

6- Você diria que conhece o seu público alvo?

7- O que é mais importante para o consumidor no momento da compra? (Características do produto - Preço, Sabor/Estilo, Indicação, Marca)

8- Como você enxerga o movimento de consumo de cerveja artesanal no Brasil? E no Rio de Janeiro?

9- Qual informação sobre o público alvo você considera mais importante? 


\section{Anexo 2 - Questionário - Fonte: Autor.}

Olá!

Gostaria de contar com a sua colaboração na pesquisa. O objetivo é aumentar o conhecimento sobre os fatores que influenciam o processo de compra dos consumidores de cervejas artesanais no Rio de Janeiro.

Por favor, seja sincero e não se preocupe, não existem respostas certas.

A duração média do questionário é de 5 minutos.

Todos os dados serão tratados de forma anônima.

\section{Obrigado pela sua participação!}

Q1. Como você define o seu grau de consumo/envolvimento com o mercado de cervejas artesanais? Marque o valor que você considera representar o seu grau de envolvimento: onde 0 significa nada envolvido e 10 significa muito envolvido. 
Q2. Qual o valor mensal médio gasto com cervejas artesanais?

De $R \$ 0,00$ a $R \$ 50,00$

De $R \$ 51,00$ a $R \$ 100.00$

De $R \$ 101,00$ a $R \$ 150,00$

De $R \$ 151,00$ a $R \$ 200,00$

Mais de $R \$ 201,00$

Q3. Agora, serão apresentados cartões com algumas combinações entre as opções de Preço, Sabor, Indicação e Marca. Ordene numerando os cartões (1-12) evitando a repetição de números, considerando o número 1 como a melhor combinação entre os cartões e o número 12 como a pior combinação. (Considere que os valores indicados no variável preço, se referem a garrafas de $600 \mathrm{ml}$ )

\section{Cartão 1}

\begin{tabular}{|c|c|}
\hline \multicolumn{2}{|c|}{ Cartão 1} \\
\hline Preço & RS 24,90 \\
\hline Sabor/Estilo & IPA \\
\hline Indicação & Vendedor \\
\hline Marca & Hocus Pocus \\
\hline
\end{tabular}

\section{Cartão4}

\begin{tabular}{|c|c|}
\hline \multicolumn{2}{|c|}{ Cartäo 4 } \\
\hline Preço & RS 29,90 \\
\hline Sabor/Estilo & IPA \\
\hline Indicaçăo & Vendedor \\
\hline Marca & Hocus Pocus \\
\hline
\end{tabular}

Cartāo 7

\begin{tabular}{|c|c|}
\hline \multicolumn{2}{|c|}{ Cartio 7} \\
\hline Preço & RS 24,90 \\
\hline Sabor/Estilo & Pilsen \\
\hline Indicaçāo & Amigo \\
\hline Marca & Eisenbahn \\
\hline
\end{tabular}

Cartäo 10

\begin{tabular}{|c|c|}
\hline \multicolumn{2}{|c|}{ Cartāo 10} \\
\hline Preço & RS 29,90 \\
\hline Sabor/Estilo & Trigo \\
\hline Indicação & Blog \\
\hline Marca & Eisenbahn \\
\hline
\end{tabular}

Cartão ?

\begin{tabular}{|c|c|}
\hline \multicolumn{2}{|c|}{ Carțo 2 } \\
\hline Preço & RS 29,90 \\
\hline Sabor/Estilo & IPA \\
\hline Indicação & Blog \\
\hline Marca & Eisenbahn \\
\hline
\end{tabular}

Cartão 5

\begin{tabular}{|c|c|}
\hline \multicolumn{2}{|c|}{ Cartaio 5 } \\
\hline Preço & RS 19,90 \\
\hline Sabor/Estilo & Trigo \\
\hline Indicaçăo & Vendedor \\
\hline Marca & Hocus Pocus \\
\hline
\end{tabular}

Cartão 8

\begin{tabular}{|c|c|}
\hline \multicolumn{2}{|c|}{ Carthio 8} \\
\hline Preço & RS 19,90 \\
\hline Sabor/Estilo & Trigo \\
\hline Indicação & Vendedor \\
\hline Marca & Eisenbahn \\
\hline
\end{tabular}

Cartão 11

\begin{tabular}{|c|c|}
\hline \multicolumn{2}{|c|}{ Cartáo 11} \\
\hline Preço & RS 29,90 \\
\hline Sabor/Estilo & Pilsen \\
\hline Indicação & Amigo \\
\hline Marca & Hocus Pocus \\
\hline
\end{tabular}

Cartão 3

\begin{tabular}{|c|c|}
\hline \multicolumn{2}{|c|}{ Cartão 3} \\
\hline Preço & RS 24,90 \\
\hline Sabor/Estilo & Pilsen \\
\hline Indicaçăo & Blog \\
\hline Marca & Eisenbahn \\
\hline
\end{tabular}

Cartäo 6

\begin{tabular}{|c|c|}
\hline \multicolumn{2}{|c|}{ Cartão 6} \\
\hline Preço & RS 19,90 \\
\hline Sabor/Estilo & IPA \\
\hline Indicaçăo & Amigo \\
\hline Marca & Eisenbahn \\
\hline
\end{tabular}

Cartäo 9

\begin{tabular}{|c|c|}
\hline \multicolumn{2}{|c|}{ Cartão 9} \\
\hline Preço & RS 24,90 \\
\hline Sabor/Estilo & Trigo \\
\hline Indicaşa & Amigo \\
\hline Marca & Hocus Pocus \\
\hline
\end{tabular}

Cartão 12

\begin{tabular}{|c|c|}
\hline \multicolumn{2}{|c|}{ Carțo 12} \\
\hline Preço & RS 19,90 \\
\hline Sabor/Estilo & Pilsen \\
\hline Indicação & Vendedor \\
\hline Marca & Hocus Pocus \\
\hline
\end{tabular}


$\mathrm{Na}$ etapa a seguir será solicitado o ordenamento das variáveis que você considera ao comprar uma cerveja artesanal em diferentes cenários de consumo, para ordenar basta arrastar e soltar a opção. Considerar nesta etapa a importância de cada elemento na sua escolha, onde a primeira posição significa o elemento mais importante e a última posição o menos importante.

Q4. Considerando um cenário de compra no qual você irá presentear alguém:

Preço

Sabor

Indicação (Vendedor, Amigo, Blog)

Marca

Rótulo (Aspecto Visual)

Disponibilidade (Presença da cerveja no ponto de venda)

Q5. Considerando um cenário no qual você irá consumir a cerveja em casa:

Preço

Sabor

Indicação (Vendedor, Amigo, Blog)

Marca

Rótulo (Aspecto Visual)

Disponibilidade (Presença da cerveja no ponto de venda)

Q6. Considerando um cenário de consumo em bares/restaurantes:

Preço

Sabor

Indicação (Vendedor, Amigo, Blog)

Marca

Rótulo (Aspecto Visual)

Disponibilidade (Presença da cerveja no ponto de venda)

Q7. Qual o seu sexo?

Masculino

Feminino 
Q8. Qual a sua idade?

Entre 18 e 28 anos

Entre 29 e 39 anos

Entre 40 e 50 anos

Entre 51 e 61 anos

Acima de 62 anos

Q9. Qual a sua formação?

Médio incompleto

Médio completo

Superior incompleto

Superior completo

Mestrado

Doutorado 
Q10. Qual a sua renda média familiar mensal?

Até $\mathrm{R} \$ 1.874,00$

Entre $R \$ 1,875,00$ a $R \$ 4.685,00$

Entre $R \$ 4.686,00$ a $R \$ 9.370,00$

Entre $R \$ 9.371,00$ a $R \$ 18.740,00$

Acima de $R \$ 18.741,00$

Encerramento do questionário e agradecimento. 